\title{
The Shapes of Commitment Development in Emerging Adulthood
}

\author{
E. Saskia Kunnen - Viviana Sappa • \\ Paul L. C. van Geert · Laura Bonica
}

Published online: 15 October 2008

(c) The Author(s) 2008. This article is published with open access at Springerlink.com

\begin{abstract}
Based on a model developed by Kunnen et al. (in: Nurmi (ed) Navigating through adolescence: European perspectives, 2001), we investigated trajectories of commitment development in university students and their relation with well-being, identity style, coping, personality, and ego-development. By means of cluster analysis on individual trajectories, we distinguished different clusters of trajectories in six domains of life. Almost all clusters could be classified according to the identity status theory, either on a moratorium-achieved trajectory (MAMA), or as a stable trajectory in one of the four identity statuses. As expected, clusters with stable strong commitment had highest levels of well-being, and MAMA clusters had highest levels of ego-development. In general, the condition "having no commitments for a prolonged period" was more strongly related to non-optimal outcomes than the condition "no exploration." This is surprising, given the important role of exploration in identity development. We suggested that having no commitments may affect-probably temporarily - the coping preferences and personality characteristics. Differences between the domains can be interpreted as effects of different societal demands and the social or non-social nature of the domain.
\end{abstract}

E. S. Kunnen $(\bowtie)$. P. L. C. van Geert

Department of Clinical and Developmental Psychology, University of Groningen, Groningen, The Netherlands

e-mail: e.s.kunnen@rug.nl

V. Sappa $\cdot$ L. Bonica

Department of Psychology, University of Torino, Torino, Italy
Keywords Identity development · Process · Trajectory

\section{Introduction}

Identity development is a life-long process that is particularly salient during late adolescence and emerging adulthood, when individuals have to make important life decisions. Although this process has been studied from different theoretical perspectives, all authors recognize its complexity in terms of the interaction between person and context. Following the Identity Status Paradigm (Marcia 1993), we consider identity as a developmental process of commitment formation following exploration, and we see commitments as the expression of the interaction between person and context (Bosma and Kunnen 2001). Commitments refer to what the person values in different domains of life.

Based on this perspective and on empirical findings, we present a model of mechanisms and processes in commitment development. The aim of this model is to make predictions about the possible shapes of developmental trajectories in emerging adulthood. Our study is organized in two parts: a first part focuses on individual pathways of commitment development in different domains of life, the second part on the validity of this differentiation by investigating how these trajectories differ with regard to psycho-social aspects such as well-being, coping, personality, and ego development.

We start with an overview of theories concerning mechanisms in identity development. Next, we describe our model of commitment development and the hypothesized trajectories. After that, we discuss the expected relations between identity development and psychosocial variables in order to define our second set of hypotheses. 
Trajectories of Identity Development

Marcia's Identity status theory, although not a developmental theory, offers important contributions for studying developmental trajectories. The four identity statuses that Marcia (1966) formulates are defined by the absence or presence of commitments and exploration. They can be considered as an extension of Erikson's bipolar description of the outcome of the identity crisis in adolescence (identity versus diffusion). The most mature status is the achieved status, in which a subject has developed commitments after a period of exploration of alternatives. A foreclosed status means that a subject has commitments without prior exploration (for example by adopting commitments from his or her parents). The moratorium status refers to a situation in which a subject does explore but did not yet form commitments, and in the diffuse status the subject has not developed commitments and does not explore.

Knowledge of the mechanisms and trajectories of identity and commitment development has rapidly increased in the past 10 years (Bosma and Kunnen 2001). Research into status-change over time suggests that there are several pathways of commitment development. In the period between middle adolescence and early 20s, the frequency of achieved identity statuses increases, and in particular the frequency of the diffuse identity status decreases (Marcia 1993). This indicates that in this period many subjects start to explore and to develop self-chosen commitments.

In adulthood, Fadjukoff et al. (2005) found progressive, regressive and stable trajectories of identity development in both general identity and in various identity domains. Bosma and Gerlsma (2003) give an overview of the trajectories that are theoretically assumed and empirically found. They conclude that in research an increasing number of types of identity development are described. The diffuse and the foreclosed status are conceived of as the more stable identity statuses because they do not involve exploration, while people who are open to identity exploration could be involved in what Marcia and colleagues (Stephen et al. 1992) called "MAMA cycles." A MAMA cycle consists of an alternation of exploration (Moratorium status) and strong commitments, chosen on the base of the exploration (Achieved status).

Mechanisms involved in the development and maintenance of trajectories include both person-centered and context-centered variables (Bosma and Kunnen 2001). Berzonsky $(1990,1992)$ gives an elaborate review of the mechanisms of the identity formation process in his studies on 'identity styles.' Identity style refers to stable interindividual differences in short-term identity processes: the way in which subjects construct and revise or maintain their sense of identity (Berzonsky 1992). Although the different styles are related to identity statuses, Berzonsky does not perceive identity development as a sequence of stages, but as a long-term process that results in different types of pathways, depending on a subject's (stable) processing style. Three different styles are distinguished, and these styles are characterized by different pathways of commitment and exploration over time. Subjects with an information-oriented style actively explore and evaluate relevant information before committing themselves. These subjects have either a moratorium-status or an achieved status. The pathways they follow are characterized by relatively high levels of exploration, and the development of strong commitments. Subjects with a normative or norm-oriented style focus on normative expectations of significant others. They typically have a foreclosed identity status. Their pathways are characterized by strong commitments that do not change, and thus do not significantly fluctuate in strength. Exploration is low. Persons with an avoidant/diffuse identity style tend to delay and procrastinate until hedonic cues in the immediate situation dictate a particular course of behavior. Their 'diffuse orientation' involves attempts to avoid confronting problems as long as possible. They typically have a diffuse identity status (Berzonsky 1990). Thus, the course of their pathway will be characterized by enduring lack of commitments and of exploration.

However, evidence for different types of foreclosed and diffused statuses (Kroger 1995; Marcia 1989) complicates the picture. This evidence suggests that some foreclosed and diffused statuses are simply foreclosed or diffused because the right trigger or motivation to explore and develop self chosen commitments has not yet presented itself. These statuses are called "developmentally" foreclosed or diffuse, as opposed to "firm" or "stable" foreclosed or diffused. In "developmentally foreclosed" and "developmentally diffused" trajectories, the foreclosed and diffused status is a starting point for identity development: they are followed by a period of exploration. The differentiation between stable and developmental trajectories makes clear that we not only focus on personal characteristics such as identity styles. Also differences in environmental factors, in the form of challenges and opportunities, play a role and may affect the shape of the trajectory (Bonica and Sappa 2006).

In the foregoing, we have discussed commitments in general. However, commitments have to be developed in different domains. The question arises whether the development of commitments should be studied per domain, or whether the development in different domains should be integrated to describe the general development of identity in a subject. In Kunnen (2005) it is argued that in the same subject, different trajectories may be found in different 
domains, because of differences in the meaning of the domain for the subject. The meaning of a domain at a given moment in time is partly individually determined, but also strongly influenced by the subject's cultural context (Côté and Levine 1987; Kunnen 2008). The context will be especially observable in the intra-individual differences in development between different domains. Commitments have to be developed in different domains of life (Bosma 1985), but not all commitments develop at the same time. The demands and challenges for identity development in different domains are affected by cultural, societal, and personal factors in different ways. For example, we expect to find more developmentally foreclosed and diffused commitments in domains in which society generally does not offer challenges or does not compel the subject to make choices. Life-events, partly socially established, determine the exposure to challenges in different domains. Entering university is a normative transition that happens to many young people in Western society. Because of our specific interest in commitment development, we consider it an interesting moment in which students are asked to cope with a new kind of studies, new choices for a future profession, and a new system of relations with peers and adults. Vleioras (2005) has shown that not only timing of challenges, but also the type of the domain may differentiate between the patterns of development. For example, he found exploration to be less important in social domains. These differences between domains will probably manifest themselves in the type of trajectories that are found in each domain.

\section{A Model of Commitment Development}

In this section, we will describe a model of commitment development that is based on the theories that are discussed in the previous section. This model is described in more detail by the first author and colleagues in Kunnen et al. (2001). The core of the model is the assumption that commitments develop in a long series of daily life events. These events may support or challenge the existing commitment. Enduring and serious challenge may result in a conflict (Bosma and Kunnen 2001) which manifests itself by an increase in exploration and a decrease in the strength of commitments and may result in the growth of new, better adjusted commitments. Kunnen (2006) suggests that in case of a conflict, the first step is an increase in exploration, while the decrease in strength of commitments follows a little later. That means that in case of a conflict and change of commitment, decreasing levels of commitment are related to increasing levels of exploration. This assumption is confirmed by the finding of Kunnen (2005) that on the intra-individual level, over time strong negative correlations exist between exploration and commitments in subjects who are in the midst of a commitment change, while the correlations are much lower in subjects in a stable phase. Thus, the patterning of conflicts and supportive events is one of the major mechanisms in the model that determines the shape of a trajectory.

A second important aspect of the model concerns interindividual differences in how individuals cope with conflicts. Based on Berzonsky's theory of identity styles and Marcia's descriptions of differences between the statuses, we formulated a factor in the model that represents interindividual differences in the tendency to accommodate (adjust their commitments in case of a conflict) or to assimilate (i.e., adjust conflicting information is such a way that it fits in with the existing commitment). A strong tendency to accommodate, comparable to a diffuse identity style, results in frequently changing and weak commitments, while a strong tendency to assimilate, comparable to a normative style, results in strong and stable commitments. Based on this conceptual model, a mathematical dynamic systems model was developed. With this model, we simulated trajectories of commitment development with different patterns of challenging events and different ratios of assimilation versus accommodation tendencies. It shows that a strong tendency to assimilate results in trajectories with stable strong commitments. A strong accommodation tendency results in stable trajectories with weak commitments. A balanced assimilation-accommodation tendency may result in stable commitments, or in fluctuating commitments, depending on the patterning of conflicts. In Fig. 1, we present abstracted shapes of the trajectories that are generated by the model.

Figure 1a shows individual trajectories of commitment strength and exploration in a fluctuating trajectory. The commitment trajectory is based on the simulations, the shape of the exploration is based on the theoretical and empirical findings that exploration increases in case of a conflict and decreases after the conflict. The figure shows a crisis in the commitments: the commitment strength is high at the beginning, but decreases while the exploration increases. After a period of exploration, a new commitment starts to grow, and the exploration level decreases. The emotions that are depicted at the $x$-axis will be discussed later on. Figure $1 \mathrm{~b}$ shows the commitment and exploration trajectories in case of a developmentally and a firm foreclosure. Both cases start with a foreclosed status: strong commitments and low levels of exploration. The firm foreclosed case continues in that way during the whole period. The developmentally foreclosed case shows a crisis, characterized by a decrease in commitment strength and an increase in exploration. Figure 1c shows a developmentally and a firm diffuse case. The firm diffuse case has low levels of commitment and of exploration during the whole period. The developmentally diffuse case shows 
Fig. 1 Hypothesized trajectories of MAMA cycle (a), stable and developmental foreclosure (b), and stable and developmental diffuse (c)
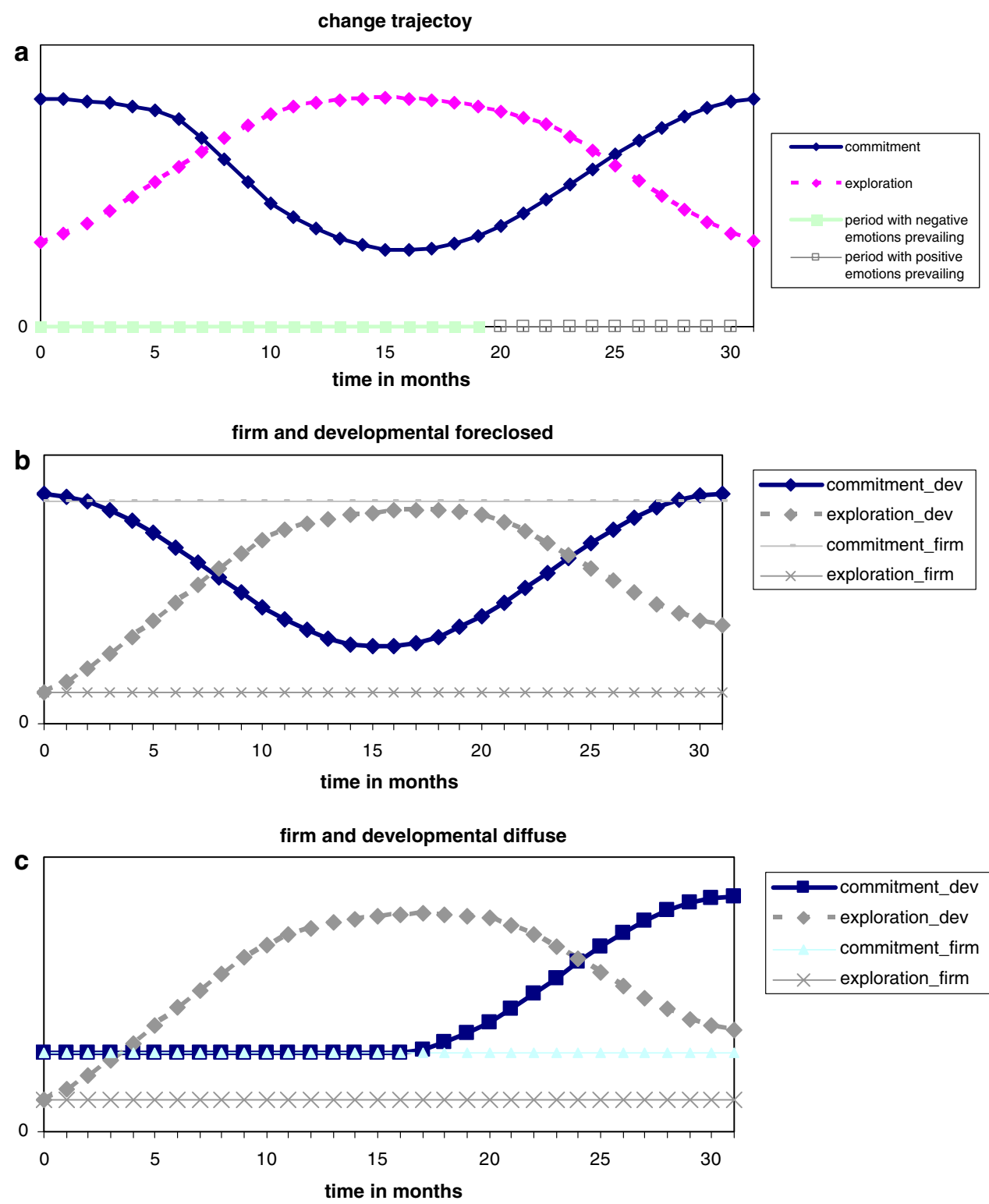

initially a diffuse status, but then exploration begins, and after a period of exploration a commitment develops. In the developmental cases, the accommodation/assimilation tendency is balanced, in the firm foreclosed case there is a high tendency to assimilate, in the firm diffuse case there is a high accommodation tendency.

The $x$-axis represents time. The model does not give direct clues about the time scale of the process. Although there are only few hard empirical data, some evidence suggests that the time scale for the change of a commitment, i.e., the period between the beginning and the end of the trajectories in Fig. 1a, may cover months or even years (Kunnen 2008). This means that within the scope of this study, a six-month period, on the individual level we probably see only a part of a complete change trajectory. Described in terms of the various different statuses, in Fig. 1a we see different phases. The first is the change from Achievement to Moratorium (AM), with weakening commitment and an increasing exploration, the second the period of Moratorium (M), and the third is the change from Moratorium to Achievement (MA) in which the level of exploration decreases, and the person reaches a new commitment. Of course, the choice for three phases is arbitrary, it is based on an educated guess that a transition may take about 2 years.

In this paper, we will try to find empirical evidence for the shapes of the trajectories as described in Fig. 1. Based on two measurements, 6 months apart, we expect to find: 
(1) Stable foreclosed trajectory with strong commitments and low exploration (low accommodation tendency),

(2) Stable diffuse trajectory with weak commitments and low exploration (high accommodation tendency),

(3) Stable achieved trajectory, with strong commitments and exploration (balanced accommodation-assimilation tendency),

(4) MAMA trajectory, phases of the trajectory shown in Fig. 1a (balanced tendency, with conflict). There will be considerable variation within this trajectory, depending on the phase of development. We expect that each MAMA cluster can be placed in one of the phases depicted in Fig. 1a.

Based on the model three other trajectories can be expected. However, because they are probably less common, there is less chance of finding them:

(5) Developmental foreclosure, consisting of a period with very low exploration and high commitment at $\mathrm{T} 1$, followed by a moratorium or achieved status at T2.

(6) Developmentally diffused, consisting of a period with low commitment and low exploration at $\mathrm{T} 1$, followed by increase in exploration, and finally growth of commitment at $\mathrm{T} 2$.

(7) Stable moratorium trajectories. Moratorium is theoretically considered to be a temporary phase. Little is known, however, about the duration, and there is some evidence that this phase may last for several years (see Luyckx 2006), in which case we would find low levels of commitment and high levels of exploration at $\mathrm{T} 1$ and $\mathrm{T} 2$. This trajectory is the second of the three phases we distinguish in the MAMA cycle in Fig. 1a.

We expect differences between domains, because they differ in the need for identity work and in the role of exploration (between social and non-social domains). It is difficult to predict how this will manifest itself in the different trajectories, so it will be studied exploratively.

Relation Between Trajectories and Well-being, Maturity, Personality, and Coping

In the first step of this study, we aim to distinguish the different types of trajectories in identity development described above. In this second part, we will explore the validity and relevance of this differentiation, by investigating whether the types differ with regard to aspects of well-being, coping, personality, and ego-development.

First, we will discuss the implications of our model with regard to these differences. We will relate these implications to empirical findings that are found in the literature. However, most research has focused on those relationships at one point in time. In our study, we focus on trajectories, and our model allows us to make predictions about the relations with different types of trajectories.

With regard to well-being, the concept of conflict in our model is important. Conflicts result in a decrease of commitments. Assuming that the presence of conflicts will be related to a low well-being, we may thus predict that trajectories that are characterized by a decrease of commitments or low commitments will be related to lower levels of well-being. Research shows that a lack of commitments predicts a low degree of well-being. It is thus important that people deal with identity issues, but how they do so, thus whether they have foreclosed or achieved commitments, is not related to well-being (Vleioras 2005). Thus, we expect subjects in trajectories with stable strong commitments to have more positive and less negative feelings concerning their commitments in that domain than subjects without strong commitments. Because the emotions are assessed at T2, we expect that in changing trajectories, the levels of exploration and commitment at $\mathrm{T} 2$ will be most important, as shown in Fig. 1a.

With regard to ego-development, we have argued (Bosma and Kunnen 2001) that too much assimilation results in rigidity and distortion of reality, while too much accommodation results in chaotic and superficial commitments. A well-balanced ratio between assimilation and accommodation, between changing the personal aspects and changing the contextual aspects, results in optimal adaptation and development. Research shows that subjects with an achieved or moratorium-status have higher levels of ego-development (Marcia 1993). In our study, trajectories with high levels of exploration (achieved or moratorium) in at least one of the measurement points are thus expected to have higher levels of ego-development. Subject with low levels of commitment and exploration at both times (diffuse) will have the lowest levels of egodevelopment.

With regard to personality, we expect that balanced levels of assimilation and accommodation (thus the achieved and moratorium statuses) are related to higher levels of conscientiousness and openness, and lower levels of neuroticism. The model does not allow us to formulate predictions with regard to agreeableness. Empirical evidence supports our assumptions. Berzonsky and Sullivan (1992) found subjects with a diffused status to be less conscientious, open and introspective than subjects with other identity styles. They also have lower scores on agreeableness (Clancy and Dollinger 1993), while subjects with diffused and foreclosed statuses also score lower on autonomy ratings (Marcia 1993). Moratorium and achieved statuses are negatively related to neuroticism (Clancy and Dollinger 1993). 
We thus expect subjects with strong commitments at least one of the times to score highest on the personality scales of conscientiousness, agreeableness, and emotional stability, and subjects with low scores for commitment and exploration at both times to score lowest. We expect subjects in an achieved trajectory to have the highest, and subjects in the diffuse trajectory to have lowest scores on autonomy compared to the other subjects.

Different types of coping can be described with regard to their differences in assimilation and accommodation ratio. Especially problem focused or active coping can be seen as related to a balanced ratio, while passive or avoidant types of coping are conceptually related to high levels of accommodation, thus avoiding conflicts by changing the commitments. Subjects with a diffuse status are found to score high on emotion-focused, avoidant, and passive ways of coping (Marcia 1993). We therefore expect subjects with low scores on exploration and commitments to score highest on passive and avoidant coping.

Finally, we will compare the trajectories with regard to identity style. Our model was based partly on Berzonsky's identity styles, because these styles are described in terms of underlying mechanisms of assimilation and accommodation. We expect trajectories with stable high levels of commitment and low exploration to be related to higher levels of normative identity styles, and low levels of information-oriented styles. Trajectories with low levels of commitment and exploration will be related to high levels of diffuse style, and low levels of both other styles. The trajectories that show change in commitments and exploration, or high levels of both, are expected to have a positive relation with the information-oriented style.

As an additional means of validation, we will compare the trajectories with regard to the subjects' perception of change in their commitments. We expect that trajectories that show much change will have higher levels of perceived change.

\section{Method}

Subjects were 89 first year Dutch psychology students (aged mainly 18-23 years, 19 males and 70 females). As discussed, we expect that this group will show prominent identity development. In late adolescence, much identity work takes place and new students are in a transitional phase in many domains of their lives. Participation as a subject in research is part of the curriculum of our subjects. The subjects were free however in selecting the study in which they wanted to participate as subject.

Strength and content of the commitments and the amount of exploration were assessed by means of the Groningen Identity Development Scale (Bosma 1985). The GIDS consists of a semi-structured identity interview. This interview is organized by domain and covers the domains: philosophy of life, parents, friends, studies, self, and intimate relationships. In each domain a short interview was first administered, meant to stimulate the subject to think about what was important to her/him in that specific domain. Next, the subject was asked to write on a card what was most important in this domain: the commitment. Next, a questionnaire was administered about this commitment. This resulted in a score for the strength of the commitment (range 0-36), and for the amount of exploration (range 0-24) in that domain. The commitment scales in all domains had an alpha score above 0.80 . The alpha of the exploration scale in the domain study work leisure was 0.65 , the exploration scales of all other domains had an alpha above 0.70 . Strength of commitment is measured by items such as: "Does this.... (commitment)... give you the feeling that you know what you want to do with your life?" "Are you satisfied with .....(commitment)...?"

Some examples of questions measuring exploration are: "Do you talk with others about ... (name of the domain)?" "Do you try to develop another (commitment) on this topic?"

Both the commitment scale and the exploration scale consist of two factors: commitments consist of the factor "direction," expressing a sense of support, strength, and direction, and the factor "identification," expressing involvement in and identification with the commitment. The exploration scale consists of the factor "orientation" expressing an active orientation toward other people, and the factor "change," expressing active attempts to come to a new commitment (Bosma 1985). However, in our research the correlation between both factors within each scale turned out to be very high (above 0.90) and we used only the total scores for each scale.

The GIDS was administered twice: once shortly after the start of the first year of Bachelor in November-December (T1), and the second time at the end of the first year of study, in May-June (T2).

Before the first interviews, in October, various personality inventories were administered. Information processing styles were assessed by a Dutch translation of the ISI (Berzonsky 1990). This is a self-report instrument that measures the preference for the information-oriented, normative and diffuse identity style. The reliability of the information oriented and the diffuse scale was sufficient (alpha is .66 and .68), but the reliability for the normative scale was rather low (alpha .49). The normative scale has a range from 9 to 45 , the diffuse scale from 10 to 50, and the information-oriented scale from 11 to 55 .

Personality traits were assessed by the FFPI, a Dutch Big Five questionnaire (Hendriks et al. 1999). In this questionnaire, subjects have to indicate for 100 statements 
how true that statement is for them. The FFPI uses the scale "autonomy" as fifth scale instead of the in Big Five research often used "openness to experience." This autonomy scale assesses the preference for independent thinking, forming one's own opinion. We used the scales Conscientiousness, Emotional Stability, Agreeableness, and Autonomy for which we formulated hypotheses. This implies that the scores on Extraversion were not included in this article. All scales range from 0 to 100 . The reliability scores (alpha) for the four scales are all between .80 and .95 .

Coping is assessed with the UCL-A (Utrecht Coping List for Adolescents), a Dutch self-report instrument for assessing coping styles based on the theory of Lazarus (Bijstra et al. 1994). The UCL-A consists of seven scales: active coping, palliative reactions, avoidance, seeking social support, passive or depressed coping, expression off emotion, reassuring thoughts. In this study, we use only the active, passive, and avoidant scale. The subject is asked on a 4-point scale to indicate how often he or she uses concrete ways of coping with a problem. For example: "I try to avoid the problem." "I start to think about different ways to solve the problem." The reliability (alpha) of these scales was .69, .68, and .71 , respectively. The passive and active coping scales range from 7 to 28 , the avoidant coping scale from 8 to 32 .

The level of ego-development was administered by the ZALC (Zinnen AanvulLijst Curium, in English Sentence Completion List Curium), a Dutch version of Loevinger's sentence completion test (Westenberg et al. 2000). In this instrument, the level of ego-development is assessed by means of the categorization of 32 completed sentences. The first author has received a training to be able to assign the sentences to the various categories. The categorizations are based on Loevinger's descriptions of the different levels of ego-development, and the measurements result in one indication of the subject's level of ego-development. Level (score) 3 indicates the self-protecting stage, level 4 the conformist stage, level 5 the self-aware stage, and 6 the conscientious stage.

Immediately following the second identity interview, we showed the subjects the two cards with their commitments at T1 and T2. The following questions were asked:

"Do you feel your commitment has remained stable or that it has changed?" They rated the change on a 5-point scale $(0=$ stable, $4=$ very great change). This score is used as indication of perceived change in the content of the commitment.

"Do you have positive feelings about this (change or stability)...?" The subjects rated this on a 5-point scale ( $0=$ no positive feelings, $4=$ very strong positive feelings). "Do you have negative feelings about this ... (change or stability)?" The subjects rated this on a 5-point scale $(0=$ no negative feelings, $4=$ very strong negative feelings).

We analysed the data per domain. To find different types of trajectory, we carried out a cluster analysis for each domain separately (SPSS version 11). For this cluster analysis, we used variables that are based on the GIDS scores for strength of commitment and exploration at T1 and T2. Because we were interested in the shapes of the trajectories, we firstly use two variables that describe the change over time: (a) the difference between commitment value at T2 and at T1 (Dif_c) and (b) the difference between exploration value at T2 and at T1 (Dif_e).

However, not only the change is important, but also the overall level of commitment and exploration. This level is represented by the average level of both variables: (a) the average commitment between T1 and T2 (M_c); (b) the average exploration between T1 and T2 (M_e). Resuming, the cluster analysis is based on four variables: Dif_c, Dif_e, M_c, and M_e.

One of the risks of cluster analysis is that each method has its own flaws and biases. A good way to test the validity and stability of the solution found is to compare the results from different methods. If different methods result in comparable clusters, this is evidence of the validity of the findings (Everitt et al. 2001).

We performed cluster analyses using at first Ward's method in order to optimize the minimum variance within clusters (Ward 1963). We choose a cluster solution on the basis of three arguments: values of fusion coefficients, theoretical arguments (the interpretability of the solution), and the differences between the clusters with regard to all four variables. To optimize the clusters, we applied the $\mathrm{K}$-mean cluster method with the chosen solution as initial center. We checked the cross-method stability of the clusters by means of a lambda test with the outcomes of clustering using Average linkage. A comparison between Ward's and Average linkage methods could be considered a good strategy (cf. Blashfield; Borgen and Barnett 1987). Finally, we completed the validation by using discriminant analysis.

For each cluster, we computed the mean score on each of the four variables and these means were used to label the clusters. We classified the clusters in terms of the identity statuses according to the following rules. The change scores (Dif_c and Dif_e) were interpreted as indicating a significant change if their value was more than the average change within the cluster plus or minus $1 / 2$ standard deviation.

We differentiated between different phases in the MAMA cycle: AM, with decreasing commitment strength and increasing exploration and MA with increasing commitment strength and decreasing exploration. If Dif_c and Dif_e have a value between the average change minus $1 / 2$ 
standard deviation and average change plus $1 / 2$ standard deviation, we classify the trajectory as stable. We interpreted the stable trajectories and the separate measurement points according to the following rules:

- Moratorium if $\mathrm{C}$ is below and $\mathrm{E}$ above average.

- Diffuse if $\mathrm{C}$ and $\mathrm{E}$ are below average.

- Foreclosed if $\mathrm{C}$ is above and $\mathrm{E}$ below average.

- Achieved if $\mathrm{C}$ and $\mathrm{E}$ are above average.

For all domains, the Kolmogorov-Smirnov test (for one sample, non-parametric) indicated that the variables which were used for the cluster analysis show a normal distribution.

\section{Results I}

\section{Results I: Cluster Outcomes}

The number and type of clusters are different for each domain. We therefore present the outcomes per domain.

\section{Philosophy of Life}

The 7 cluster solution turned out as best theoretically interpretable (Table 1). ${ }^{1}$

Clusters 1, 3, and 4 are interpreted as stable trajectories. Cluster 1, with above average commitment strength and exploration, as an achieved trajectory, cluster 3, with low strength and little exploration, as a diffused trajectory, and cluster 4 , with a lot of exploration and low strength, as a moratorium-trajectory. Clusters 2, 5, 6, and 7 all show a change that could be part of a MAMA trajectory. Clusters 2 and 6 are theoretically comparable: both are situated at the beginning of a moratorium-period (AM), exploration is high and stable and commitment strength is decreasing. Subjects in cluster 6 are more extreme as compared to cluster 2: they show a dramatic decrease of commitment strength and are at the beginning of a crisis. Subjects in clusters 5 and 7 are both in the process from moratorium to achieved (MA): commitment is increasing and there is some decrease in exploration. They differ in the phase and the rate of change of the process: subjects in cluster $7 \mathrm{do}$ have strong commitments at time 2 due to a very rapid increase of their commitment strength, whereas subjects in cluster 5 show a slower change rate and did not reach strong commitments yet at time 2 .

\footnotetext{
${ }^{1}$ Comparison with the average-linkage solution resulted in a lambda of .77 $(p<0.001)$. Discriminant analysis classified correctly $94.6 \%$ of the cases.
}

\section{Parents}

Based on the agglomeration schedule in particular, we choose for a 6 cluster solution (Table 2). ${ }^{2}$

Clusters 1, 2, 3, and 4 are stable. Cluster 1 is interpreted as a foreclosed status: strong commitments and little exploration, while cluster 3 is interpreted as a moratoriumstatus (high exploration and low strength) and cluster 4 as a diffused one: low strength and exploration. Subjects in cluster 2 are comparable with subjects in cluster 1: strong commitments, little exploration, and little change. Theoretically, we do not expect the differences to result in relevant differences in identity, and we interpret cluster 2 as a second foreclosed cluster. We will come back to these results later. Subjects in cluster 5 may be at the beginning of a moratorium-period: exploration is high and stable and commitment strength is decreasing. Subjects in cluster 6 can be considered as being in progress toward an achieved status: commitment is increasing and above average at $\mathrm{t} 2$, while exploration is decreasing from an initially high value. Surprising in this domain is the absence of a stable achieved cluster and, instead, the finding of two large clusters of stable foreclosure. In general, both the amount of change and the exploration in this domain are very low, as compared to the other domains, and relatively many subjects have stable high commitments.

\section{Friends}

On the basis of the agglomeration schedule, Ward's cluster analysis suggested a 5 cluster solution ${ }^{3}$ (Table 3 ).

Cluster 1 has a stable low exploration level and an increase in strength of commitment, implying a change from diffusion to foreclosure. This development is difficult to interpret theoretically, and we will return to it in the discussion. Cluster 2 is stable, with strong commitments and little exploration. It is interpreted as a foreclosed cluster. Subjects in cluster 3 are at the beginning of the transition from a moratorium-status towards an achieved status: commitment strength is increasing from an initially low value and there is some decrease from an initially high value in exploration. Subjects in cluster 4 have stable, strong commitments and above average levels of exploration, so this may be considered an achieved cluster. Subjects in cluster 5 may be at the beginning of a moratorium-period: exploration level is high and the commitment strength is rapidly decreasing. Surprising in

\footnotetext{
${ }^{2}$ Comparison with the average linkage solution resulted in a lambda of .48 $(p<0.001)$. Discriminant analysis classified correctly $97.8 \%$ of the cases.

${ }^{3}$ Comparison with the average linkage solution resulted in a lambda of $.096(p<0.01)$. Discriminant analysis classified correctly $92.4 \%$ of the cases.
} 
Table 1 Mean scores per cluster for mean and changes in commitment and exploration in domain philosophy of life

\begin{tabular}{llllllrrr}
\hline & $\begin{array}{l}\text { Cluster 1 } \\
\text { A }(n=39)\end{array}$ & $\begin{array}{l}\text { Cluster 2 } \\
\text { AM }(n=13)\end{array}$ & $\begin{array}{l}\text { Cluster 3 } \\
\text { D }(n=18)\end{array}$ & $\begin{array}{l}\text { Cluster 4 } \\
\text { M }(n=7)\end{array}$ & $\begin{array}{l}\text { Cluster 5 } \\
\text { MA }(n=11)\end{array}$ & $\begin{array}{l}\text { Cluster 6 } \\
\text { AM }(n=2)\end{array}$ & $\begin{array}{l}\text { Cluster } 7 \\
\text { MA }(n=3)\end{array}$ \\
\hline Dif_c & $1.1 \mathrm{a}(3.07)$ & $-9.4 \mathrm{~b}(2.9)$ & $-1.6 \mathrm{c}(2.3)$ & $-1.9 \mathrm{ac}(3.5)$ & $5.5 \mathrm{~d}(1.8)$ & $-24 \mathrm{e}(5.6)$ & $18.3 \mathrm{f}(4.5)$ & $72.504^{* * *}$ \\
Dif_e & $-2.0(2.9)$ & $-0.1(3.4)$ & $-0.2(3.5)$ & $-2.7(3.5)$ & $-2.1(3.4)$ & $5(4.2)$ & $-1.7(6.1)$ & $2.407 *$ \\
M_c & $30.6 \mathrm{a}(2.09)$ & $23.4 \mathrm{~b}(2.6)$ & $22.7 \mathrm{~b}(3.61)$ & $11.36 \mathrm{c}(3.6)$ & $18.7 \mathrm{~d}(3.5)$ & $17 \mathrm{bcd}(1.4)$ & $17.5 \mathrm{bcd}(6.1)$ & $64.255^{* * *}$ \\
M_e & $14.4 \mathrm{a}(3.1)$ & $15.7 \mathrm{a}(2.7)$ & $9.9 \mathrm{~b}(2.75)$ & $16.1 \mathrm{a}(4.6)$ & $13.8 \mathrm{a}(2.6)$ & $15 \mathrm{ab}(0)$ & $14.2 \mathrm{ab}(4.6)$ & $6.526^{* *}$ \\
\hline
\end{tabular}

Note: $\mathrm{df}=6,86$. Means with different letters in the same row differ significantly at $p<.05$ using Bonferroni's multiple comparisons procedure Stability in commitment: $-4.2<$ dif_c $<2.8$

Stability in exploration: $-3.05<$ dif_e $<0.45$

$* p<.05 ; * * p<.01 ; * * * p<.001$

Table 2 Mean scores per cluster for mean and changes in commitment and exploration in domain parents

\begin{tabular}{|c|c|c|c|c|c|c|c|}
\hline & $\begin{array}{l}\text { Cluster } 1 \\
\mathrm{~F}(n=27)\end{array}$ & $\begin{array}{l}\text { Cluster } 2 \\
\mathrm{~F}(n=19)\end{array}$ & $\begin{array}{l}\text { Cluster } 3 \\
\mathrm{M}(n=10)\end{array}$ & $\begin{array}{l}\text { Cluster } 4 \\
\mathrm{D}(n=11)\end{array}$ & $\begin{array}{l}\text { Cluster } 5 \\
\mathrm{AM}(n=15)\end{array}$ & $\begin{array}{l}\text { Cluster } 6 \\
\text { MA }(n=10)\end{array}$ & $F$ \\
\hline Dif_c & $-1.3 \mathrm{a}(2.42)$ & $2.1 \mathrm{~b}(2.41)$ & $0 \mathrm{ab}(4.7)$ & $1.9 \mathrm{ab}(3.3)$ & $-8.4 \mathrm{c}(4.2)$ & $9.5 c(4.3)$ & $37.283 * * *$ \\
\hline Dif_e & $-0.4 \mathrm{ab}(3.0)$ & $-1.0 \mathrm{ab}(2.7)$ & $1.5 b(4.3)$ & Oab (4.7) & $2.1 \mathrm{~b}(3.9)$ & $-3.9 b(5.5)$ & $3.511 * *$ \\
\hline M_c & $33 a(1.7)$ & $28.2 \mathrm{~b}(2.1)$ & $13.1 \mathrm{c}(2.5)$ & $20.1 \mathrm{~d}(2.4)$ & $24.8 \mathrm{e}(3.1)$ & $24.9 \mathrm{e}(3.2)$ & $117.025^{* * *}$ \\
\hline M_e & $9.3 \mathrm{ab}(2.4)$ & $8.7 b(2.3)$ & $18.3 \mathrm{c}(2.5)$ & $8.4 \mathrm{ab}(2.4)$ & $11.8 \mathrm{a}(4.3)$ & $16 \mathrm{c}(2.9)$ & $25.871 * * *$ \\
\hline
\end{tabular}

Note: $\mathrm{df}=5,86$. Means with different letters in the same row differ significantly at $p<.05$ using Bonferroni's multiple comparisons procedure Stability in commitment: $-5.7<$ dif_c $<5.9$

Stability in exploration: $-2.25<$ dif_e $<1.85$

$* * p<.01 ; * * * p<.001$

Table 3 Mean scores per cluster for mean and changes in commitment and exploration in domain friends

\begin{tabular}{|c|c|c|c|c|c|c|}
\hline & $\begin{array}{l}\text { Cluster } 1 \\
\mathrm{DF}(n=24)\end{array}$ & $\begin{array}{l}\text { Cluster } 2 \\
\mathrm{~F}(n=26)\end{array}$ & $\begin{array}{l}\text { Cluster } 3 \\
\text { MA }(n=14)\end{array}$ & $\begin{array}{l}\text { Cluster } 4 \\
\mathrm{~A}(n=16)\end{array}$ & $\begin{array}{l}\text { Cluster } 5 \\
\text { AM }(n=12)\end{array}$ & $F$ \\
\hline Dif_c & $5.6 \mathrm{a}(3.0)$ & $-1.9 \mathrm{~b}(2.7)$ & $6.1 \mathrm{a}(6.5)$ & $-0.3 b(2.9)$ & $-11.7 \mathrm{c}(4.2)$ & $51.570 * * *$ \\
\hline Dif_e & $0.3 \mathrm{ab}(3.6)$ & $-2.7 b(3.3)$ & $-2.7 b(4.9)$ & $4.3 \mathrm{c}(2.8)$ & $3.3 \mathrm{ac}(6)$ & $11.179 * * *$ \\
\hline M_c & 27.8a (2.6) & $31.4 \mathrm{~b}(3.4)$ & $20.9 c(4)$ & $31.2 b(2)$ & 25.4a (3.9) & $30.338 * * *$ \\
\hline M_e & $9.4 \mathrm{a}(2.1)$ & $10.4 \mathrm{a}(2.2)$ & $14.1 \mathrm{~b}(3.0)$ & $15.1 \mathrm{~b}(3.1)$ & $14.2 b(3.3)$ & $17.664 * * *$ \\
\hline
\end{tabular}

Note: $\mathrm{df}=4,87$. Means with different letters in the same row differ significantly at $p<.05$ using Bonferroni's multiple comparisons procedure Stability in commitment: $-3.4<$ dif_c $<3.6$

Stability in exploration: $-2.4<$ dif_e $<2.4$

$* * * p<.001$

this domain is the absence of a diffused cluster and a moratorium-cluster, i.e., of clusters with lasting absence of commitments. The average commitment score is higher than in all other domains. Apparently, most subjects have commitments in this domain.

\section{School, Work, and Leisure Time}

On the basis of the agglomeration schedule, Ward's cluster analysis suggested a 6 cluster solution ${ }^{4}$ (Table 4).

\footnotetext{
${ }^{4}$ Comparison with the average linkage solution resulted in a lambda of $.59(p<0.001)$. Discriminant analysis classified correctly $96.7 \%$ of the cases.
}

Clusters 1, 3, and 5 are stable. Subjects in cluster 1 are in an achieved trajectory, with strong commitments and above average levels of exploration. Cluster 3 is interpreted as a moratorium-trajectory, with low scores on strength and high exploration scores. Subjects in cluster 5 are in a foreclosed trajectory: stable strong commitments, little exploration. Cluster 2 can be interpreted as a crisis cluster: an abrupt disappearance of the commitment, combined with strongly increasing exploration. Subjects in cluster 4 are developing towards an achieved status: commitment is increasing from an initially low value and there is some decrease in exploration. Cluster 6 shows the beginning of a moratorium-period, but less dramatically than cluster 2 . 
Table 4 Mean scores per cluster for mean and changes in commitment and exploration in domain school, work, and leisure

\begin{tabular}{|c|c|c|c|c|c|c|c|}
\hline & $\begin{array}{l}\text { Cluster } 1 \\
\text { A }(n=18)\end{array}$ & $\begin{array}{l}\text { Cluster } 2 \\
\text { AM }(n=12)\end{array}$ & $\begin{array}{l}\text { Cluster } 3 \\
\mathrm{M}(n=17)\end{array}$ & $\begin{array}{l}\text { Cluster } 4 \\
\text { MA }(n=9)\end{array}$ & $\begin{array}{l}\text { Cluster } 5 \\
\mathrm{~F}(n=22)\end{array}$ & $\begin{array}{l}\text { Cluster } 6 \\
\text { FM }(n=14)\end{array}$ & $F$ \\
\hline Dif_c & 2.9a (3.0) & $-14.5 b(3.4)$ & $-4.1 \mathrm{c}(3.0)$ & $11.8 \mathrm{~d}(5.8)$ & $-0.1 \mathrm{a}(1.9)$ & $-5.6 \mathrm{c}(2.5)$ & $86.923 * * *$ \\
\hline Dif_e & $-2.1 \mathrm{a}(2.5)$ & $4.8 b(3.3)$ & $-1.8 \mathrm{a}(3.7)$ & $-2.6 \mathrm{a}(4.3)$ & $-1.2 \mathrm{a}(2.7)$ & $3 b(3.0)$ & $12.335 * * *$ \\
\hline M_c & 28.1a (3.3) & $20.6 \mathrm{~b}(4.9)$ & $18.8 b(2.7)$ & $16.7 \mathrm{~b}(4.6)$ & $32.7 \mathrm{c}(2.0)$ & 26a (3.7) & $50.264 * * *$ \\
\hline M_e & $17.1 \mathrm{ab}(2.4)$ & $17 \mathrm{ab}(3.9)$ & $19.6 b(2.5)$ & $15.7 \mathrm{ab}(4.4)$ & $11.8 \mathrm{c}(2.3)$ & 15.1a (3.6) & $13.926 * *$ \\
\hline
\end{tabular}

Note: $\mathrm{df}=5,86$ Means with different letters in the same row differ significantly at $p<.05$ using Bonferroni's multiple comparisons procedure Stability in commitment: $-5.6<$ dif_c $<1.9$

Stability in exploration: $-2.07<$ dif_e $<2.03$

$* * p<.01 ; * * * p<.001$

Table 5 Mean scores per cluster for mean and changes in commitment and exploration in domain personal characteristics

\begin{tabular}{|c|c|c|c|c|c|c|}
\hline & $\begin{array}{l}\text { Cluster 1 } \\
\mathrm{F}(n=36)\end{array}$ & $\begin{array}{l}\text { Cluster } 2 \\
\text { MF }(n=9)\end{array}$ & $\begin{array}{l}\text { Cluster } 3 \\
\mathrm{M}(n=12)\end{array}$ & $\begin{array}{l}\text { Cluster } 4 \\
\text { AM }(n=16)\end{array}$ & $\begin{array}{l}\text { Cluster } 5 \\
\text { MA }(n=19)\end{array}$ & $F$ \\
\hline Dif_c & $-1.5 \mathrm{ab}(3.6)$ & $9.7 \mathrm{ac}(5.5)$ & $0.3 \mathrm{c}(3.3)$ & $-12.5 \mathrm{abc}(4.1)$ & $6.4 b(4.5)$ & $63.10 * * *$ \\
\hline Dif_e & $0.3 a(3.6)$ & $-5.1 \mathrm{abc}(3.7)$ & $2.3 b(3.1)$ & $3.7 \mathrm{a}(3.4)$ & $2.7 \mathrm{c}(2.5)$ & $12.56 * * *$ \\
\hline M_c & $31 \mathrm{abc}(3.2)$ & $24.2 \mathrm{a}(3.8)$ & 16.6abc (4.8) & $24.3 b(3.5)$ & $26.1 \mathrm{c}(2.6)$ & $42.54 * * *$ \\
\hline M_e & 11.9acd (3.1) & $13.7 \mathrm{~b}(3.9)$ & $19.7 \mathrm{db}(3.0)$ & $16.7 \mathrm{a}(3.9)$ & $17 \mathrm{c}(3.6)$ & $16.08 * * *$ \\
\hline
\end{tabular}

Note: $\mathrm{df}=\ldots$ Means with different letters in the same row differ significantly at $p<.05$ using Bonferroni's multiple comparisons procedure Stability in commitment: $-4.5<$ dif_c $<3.5$

Stability in exploration: $-2.9<$ dif_e $<5.1$

$* * * p<.001$

The below average level of exploration at the first assessment (15.1-1.5) shows that these subjects start exploration from a foreclosed rather than from an achieved position, and can be interpreted as developmentally foreclosed.

\section{Personal Characteristics}

We chose the five cluster solution because it provides the best theoretical interpretation (see Table 5). ${ }^{5}$

Subjects in cluster 1 have strong and stable commitments, while the exploration level is low. This resembles a foreclosed trajectory. Subjects in cluster 2 show increasingly strong commitments, and exploration is decreasing. This indicates the growth toward an achieved situation. However, exploration is below average at time 2, and according to the classification rules this should be interpreted as the growth toward a (fore)closed status. We shall return to this issue in the discussion. Cluster 3 shows weak commitments and high exploration, resembling a moratorium-status. Cluster 4 , with a strong decrease in commitment strength and increase in exploration is interpreted as the beginning of a moratoriumperiod. Cluster 5 shows above average commitment strength

\footnotetext{
5 Comparison with other methods is not useful because those methods do not result in plausible outcomes. Discriminant analysis shows $100 \%$ correctly classified cases.
}

and exploration, with an increased commitment besides. These subjects have reached achieved commitments in between time 1 and time 2 .

\section{Intimate Relations}

A five cluster solution was best interpretable (Table 6). ${ }^{6}$

Subjects in cluster 1 show rapid increase in the strength of commitments and decrease in exploration, they seem to develop achieved commitments between $\mathrm{t} 1$ and 2 . Subjects in cluster 2 show a strong decrease in strength, and an increase in exploration, suggesting the beginning of a moratorium-period. Subjects in cluster 3 show very weak commitments and a high level of exploration. This resembles a moratorium-status. Subjects in cluster 4 have strong commitments and little exploration, indicating a foreclosed trajectory. Cluster 6 shows growth toward relatively strong commitments and average exploration, i.e., an MA trajectory in its final stage. As compared to cluster 2 , these subjects show a more gradual change in commitments.

\footnotetext{
${ }^{6}$ Comparison with the average-linkage solution resulted in a lambda of .67 $(p<0.001)$. Discriminant analysis classified correctly $97.8 \%$ of the cases.
} 
Table 6 Mean scores per cluster for mean and changes in commitment and exploration in domain intimate relations

\begin{tabular}{|c|c|c|c|c|c|c|}
\hline & $\begin{array}{l}\text { Cluster } 1 \\
\text { MA }(n=11)\end{array}$ & $\begin{array}{l}\text { Cluster } 2 \\
\mathrm{AM}(n=11)\end{array}$ & $\begin{array}{l}\text { Cluster } 3 \\
\mathrm{M}(n=17)\end{array}$ & $\begin{array}{l}\text { Cluster } 4 \\
\text { F }(n=33)\end{array}$ & $\begin{array}{l}\text { Cluster } 5 \\
\text { MA }(n=20)\end{array}$ & $F$ \\
\hline Dif_c & 13.5ab (3.7) & $-8.8 \mathrm{a} b(3.3)$ & $-0.8(4.5)$ & $-2.0 \mathrm{~b}(3.0)$ & 5.0ab (1.6) & $83.545 * * *$ \\
\hline Dif_e & $-5.0 \mathrm{a}(4.2)$ & $3.7 \mathrm{ab}(2.7)$ & $2.5 b(4.7)$ & $-1.2 \mathrm{ab}(3.5)$ & $-2.9 \mathrm{~b}(2.9)$ & $13.154 * * *$ \\
\hline M_c & $21.1 \mathrm{ab}(4.4)$ & $25.7(4.0)$ & $15.8(3.6)$ & $30.4 \mathrm{ab}(3.7)$ & $29.2 \mathrm{~b}(3.3)$ & $52.165 * * *$ \\
\hline M_e & $16.8 \mathrm{ac}(3.7)$ & $16.4 \mathrm{a}(3.6)$ & $14.4 \mathrm{bc}(4.4)$ & $11.4 \mathrm{a}(2.9)$ & $13.9 \mathrm{~b}(3.3)$ & 8.380 \\
\hline
\end{tabular}

Note: $\mathrm{df}=$ Means with different letters in the same row differ significantly at $p<.05$ using Bonferroni's multiple comparisons procedure

Stability in commitment: $-2.7<$ dif_c $<4.3$

Stability in exploration: $-2.9<$ dif_e $<1.5$

$* * * p<.001$

\section{Discussion I}

Before we present the results of the second part of the studies, we will discuss the implications of the findings of the first part.

Analysis per domain showed different types of trajectories, most of them confirming our hypotheses. We found stable clusters with characteristics of the four statuses, and clusters that show a change from either moratorium- to achievement-status or vice versa. In one case, we saw a change from foreclosure to moratorium, thus a developmentally foreclosed trajectory. Even in this short period, we found an average of $41 \%$ of change trajectories in different domains, with a peak of $54 \%$ in the domain of friends. This result confirms our assumption that the transition to university does increase the need to identity work, and is thus a well-suited period for the study of change.

Two clusters do not fit in with our expectations: cluster 1 in the domain of friendship shows an increase in strength of commitment, with a stable and very low level of exploration. In terms of statuses, this might be described as a change from diffuse to foreclosed status. Cluster 2 in the domain of personal characteristics shows a development toward achievement, but the level of exploration at time 2 is below average, and the trajectory is classified as changing from $\mathrm{M}$ to $\mathrm{F}$. In both cases, there is development without exploration. Both unpredicted types of trajectory show a development toward strong commitments with low exploration levels. Our definition of achievement includes an above average score for exploration, while Marcia's definition (1993) refers to exploration in the past. Strictly spoken, we should describe the second state of the two clusters as closed, and not as foreclosed. By closed we mean that there is no flexibility and exploration at the moment, but there may have been exploration in the past. We think there are good arguments to differentiate between a (fore-)closed and an achieved status on the basis of actual exploration. In a rapidly changing environment like ours, a flexible and self-chosen commitment (which is the outcome of a successful commitment development) requires a continuous alertness and thus some exploration to preserve the fit between this commitment and the context. Maybe the $50 \%$ cut off score that we used to differentiate between (fore)closed and achieved, is too strict, because the mean exploration score is affected by the high levels of exploration that are shown by subjects in the midst of an identity crisis. This may especially be true for the MF cluster in the domain of personal characteristics. In this domain, the exploration score of the (rather big) moratorium-cluster is the highest of all clusters in all domains, and as a consequence the average score is high as well.

A more fundamental explanation could be that the importance of exploration for commitment development differs per domain. Recently, Vleioras (2005) has argued that in interpersonal domains like friends and parents, emotion, and not exploration is the most important mechanism in developmental change. Consequently, development without exploration may be possible in these domains. This explanation is supported by the observation that the mean levels of exploration in the domains of parents and friends are much lower than in the other domains. It may also explain the somewhat surprising finding that in the domain of parents we find two big foreclosed clusters and no achieved cluster.

Another explanation for a development of commitments without exploration is offered in a study of Blustein and Phillips (1990). They showed that in career decision making both a diffused and moratorium status are strongly related to an intuitive and dependent decision making style. On the basis of these results, the authors described persons who are in a situation of identity exploration as people who may seek out relatively rapid solutions to decisional tasks in order to reduce the anxiety of the uncommitted phase of identity formation. Possibly, it is better to have a dependent commitment rather than to be uncommitted. Following this line of interpretation, we suppose that our subjects can feel 
a great urgency to make choices in the friendship domain, and for them, the anxiety and the need to reduce this may be relatively high. In favor of this hypothesis, we found that in the domain of friends there is no cluster with a persistent absence of commitments, and the mean strength score is higher than in any other domain. More in depth analysis could be useful, i.e., it could be interesting to analyse the relation of this cluster with regard to the distance from the student's parents' home. We suppose that students who left their home and their friends may feel a more urgent need to make friends.

Except for the two unexpected trajectories mentioned above, all change clusters can be placed somewhere on the MAMA trajectory, as is shown in Fig. 2, or on one of the developmentally diffused or foreclosed trajectories. The upper part of Fig. 2 shows the same trajectories as depicted in Fig. 1a. The bottom part shows the positioning of each of the change clusters with regard to time. In the column at the right side of the picture, D1-D6 refer to the domains, and c1-c7 refer to the number of the cluster in that domain. Thus, D1-c2 is cluster 2 in Domain 1 (philosophy of life), and it is positioned at the beginning of the change trajectory, characterized by decreasing levels of commitment strength and increasing levels of exploration. Cluster D1-c7 (cluster 7 of the domain philosophy of life) can be positioned at the end of the trajectory: a new commitment has begun to grow, and the level of exploration decreases again.

If we consider the different change clusters, we see huge differences in the rate of change between them. Cluster 7 in the domain of philosophy of life and cluster 1 in the domain of intimate relationships both show an increase in strength of more than two standard deviations, while cluster 6 in the domain of philosophy of life shows a comparably fast decrease. Identity theory does not offer

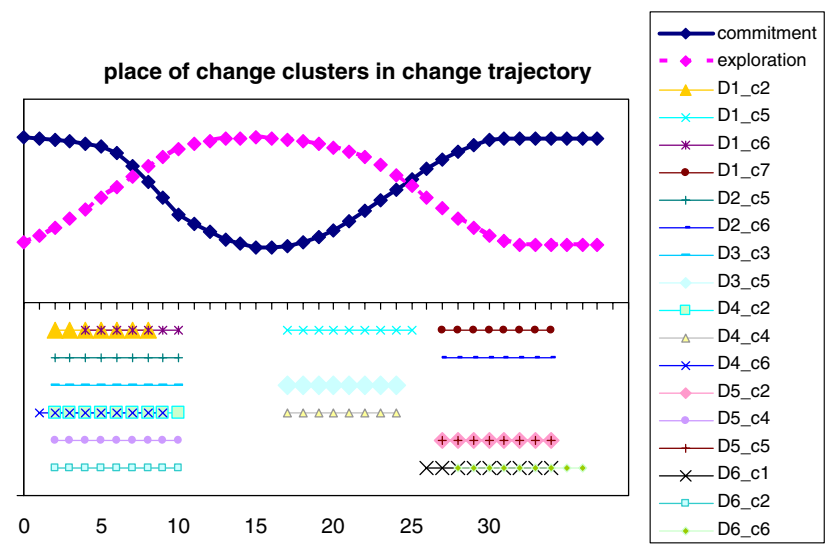

Fig. 2 The place of the change clusters in the trajectory depicted in Fig. 1a. Note: D1_c2 = domain 1, cluster 2, etc an explanation for differences in the rate of change of commitment strength. A rapid decrease can be imagined as a crisis, if a commitment suddenly turns out to be completely useless or wrong. The opposite, a suddenly emerging strong commitment could be described as a conversion.

To distinguish these rapidly changing groups from their more gradually changing counterparts, we decided to mark them as conversion and crisis in the analysis of differences between the clusters. However, we could not include the "extreme" clusters 6 and 7 in the domain of philosophy of life in the following analysis because of their small number of members.

\section{Results II}

In this section, we present the results concerning the differences between the clusters with regard to well-being, identity styles, coping, personality, and maturity (Table 7).

In the domain life philosophy, perceived change is highest in the change-clusters and the moratorium-cluster. Positive emotions are highest and negative emotions are lowest in the clusters that have (emerging) commitments, A and MA. Information-oriented identity style is highest in the A and MA clusters, and lowest in the M and D clusters. Active coping is highest in the A and AM clusters, and lowest in the crisis cluster. Finally, ego-development is highest in the A and MA clusters, lowest in the crisis cluster (Table 8).

In the domain of parents, only four variables (out of 10) differ significantly between the clusters. Perceived change is highest in the change- and moratorium-clusters. Positive emotions are highest and negative emotions lowest in the clusters with (emerging) commitments: F and MA. The M and AM clusters have lowest scores for positive emotions and highest scores for negative emotions. Emotional stability is highest in the clusters with (emerging) commitments, and lowest in the M cluster (Table 9).

In this domain, the differences with regard to perceived change and emotions are less significant than in the other domains. This may be due to predominantly strong commitments in this domain. Although all three are in the expected directions, only the negative emotion score is significant, with the lowest scores for the DF cluster. The DF cluster has the lowest score for information-oriented identity style, and the A cluster the highest. With regard to autonomy, the DF cluster has lowest scores and the F and the A cluster the highest (Table 10).

In the domain of study work and leisure too, only 4 out of 10 variables differ significantly. The greatest change is perceived in the change- and moratorium- 
Table 7 Philosophy of life: mean scores for well-being, identity styles, coping, personality, and maturity per cluster

\begin{tabular}{|c|c|c|c|c|c|c|}
\hline & $\begin{array}{l}\text { Cluster } 1 \\
\text { A }(n=39)\end{array}$ & $\begin{array}{l}\text { Cluster } 2 \\
\mathrm{AM}(n=13)\end{array}$ & $\begin{array}{l}\text { Cluster } 3 \\
\mathrm{D}(n=18)\end{array}$ & $\begin{array}{l}\text { Cluster } 4 \\
\mathrm{M}(n=7)\end{array}$ & $\begin{array}{l}\text { Cluster } 5 \\
\text { MA }(n=11)\end{array}$ & $F$ \\
\hline Perceived change & $.63(.82)$ & $1.2(1.14)$ & $.4(.62)$ & $1.3(1.11)$ & $.91(1.22)$ & 2.230 \\
\hline Positive emotions & $3.5 \mathrm{a}(.72)$ & $1.4 \mathrm{~b}(1.31)$ & $2.8 \mathrm{ac}(1.11)$ & $2.1 \mathrm{bcd}(1.6)$ & 2.8ad (1.08) & $11.059 * * *$ \\
\hline Negative emotions & $.37(.63)$ & $.83(1.19)$ & $.22(.43)$ & $.71(.76)$ & $.64(.67)$ & 1.851 \\
\hline \multicolumn{7}{|l|}{ Identity style } \\
\hline Inform. style & $41.5 \mathrm{a}(4.3)$ & 38.9ab (5.1) & $37.1 \mathrm{~b}(5.4)$ & $36.6 \mathrm{ab}(6.1)$ & 37.9ab (5.6) & $3.538 * *$ \\
\hline Norm. style & $27.5(4.47)$ & $23.6(5.09)$ & $27.5(4.24)$ & $28.3(6.13)$ & $24(4.5)$ & $2.760 *$ \\
\hline Diff. style & $23.4(4.03)$ & $26.2(5.67$ & $25.9(5.78)$ & $24.3(5.74)$ & $26.7(5.06)$ & 1.651 \\
\hline \multicolumn{7}{|l|}{ Coping } \\
\hline Avoidant coping & $3.3(.55)$ & $2.2(.63)$ & $4(.94)$ & $3.7(1.4)$ & $5.2(1.67)$ & .408 \\
\hline Passive coping & $14.9(3.18)$ & $14.2(2.38)$ & $14.2(2.9)$ & $17.1(1.95)$ & $14.6(3.59)$ & 1.358 \\
\hline Active coping & $20.1(2.73)$ & $20.1(2.97)$ & $19.6(4.03)$ & $16.9(3.18)$ & $18.3(2.41)$ & 2.106 \\
\hline \multicolumn{7}{|l|}{ Personality } \\
\hline Autonomy & $76.7(10.1)$ & $74.9(8.4)$ & $71.9(12.8)$ & $69.4(10.2)$ & $69.7(12.3)$ & 1.179 \\
\hline Conscientiousness & $67.4(11.8)$ & $59.6(14.5)$ & $70.4(11.2)$ & $63.4(7.63)$ & $64.9(9.94)$ & 1.509 \\
\hline Emotional stability & $73.1(9.98)$ & $71.5(8.23)$ & $68.6(11.7)$ & $70(6.75)$ & $69.1(13.5)$ & .588 \\
\hline Agreeableness & $80.4(5.96)$ & $78.9(10.8)$ & $77.7(12.1)$ & $76.4(10.83)$ & $79.2(12.5)$ & .306 \\
\hline Ego development & $5.0(.48)$ & $4.8(.26)$ & $4.7(.31)$ & $4.9(.19)$ & $4.7(.4)$ & $3.100 *$ \\
\hline
\end{tabular}

Note: Means with different letters in the same row differ significantly at $p<.05$ using Bonferroni's multiple comparisons procedure $* p<.05 ; * * p<.01 ; * * * p<.001$

Table 8 Parents: mean scores for well-being, identity styles, coping, personality, and maturity per cluster

\begin{tabular}{|c|c|c|c|c|c|c|c|}
\hline & $\begin{array}{l}\text { Cluster } 1 \\
\mathrm{~F}(n=27)\end{array}$ & $\begin{array}{l}\text { Cluster } 2 \\
\mathrm{~F}(n=19)\end{array}$ & $\begin{array}{l}\text { Cluster } 3 \\
\mathrm{M}(n=10)\end{array}$ & $\begin{array}{l}\text { Cluster } 4 \\
\mathrm{D}(n=11)\end{array}$ & $\begin{array}{l}\text { Cluster } 5 \\
\text { AM }(n=15)\end{array}$ & $\begin{array}{l}\text { Cluster } 6 \\
\text { MA }(n=10)\end{array}$ & $F$ \\
\hline Perceived change & $0.5 \mathrm{a}(.75)$ & $0.6 \mathrm{a}(1.1)$ & $1.7 \mathrm{ab}(1)$ & $0.8 \mathrm{ab}(.98)$ & $1.3 \mathrm{ab}(1)$ & $1.8 \mathrm{~b}(1.5)$ & $4.299 * *$ \\
\hline Positive emotions & $3.7 \mathrm{a}(.71)$ & $3.6 \mathrm{a}(.61)$ & $2.3 \mathrm{~b}(1)$ & $2.8 \mathrm{ab}(.98)$ & $2.3 b(1)$ & $3.1 \mathrm{ab}(1.3)$ & $7.607 * * *$ \\
\hline Negative emotions & $0.0 \mathrm{a}(.19)$ & $0.1 \mathrm{a}(.32)$ & $1.9 \mathrm{~b}(.92)$ & $0.4 \mathrm{a}(.67)$ & $1.1 \mathrm{bc}(.91)$ & $0.5 \mathrm{ac}(.7)$ & $17.724 * * *$ \\
\hline \multicolumn{8}{|l|}{ Identity style } \\
\hline Inform. style & $39.4(5.4)$ & $38.3(5.39)$ & $40(6.67)$ & $38.4(5.6)$ & $40.1(5.4)$ & $39.6(6.3)$ & .256 \\
\hline Norm. style & $27.7(5.3)$ & $24.9(4)$ & $28.1(5.9)$ & $25.9(4.8)$ & $25.3(4.6)$ & $27.3(3.7)$ & 1.208 \\
\hline Diff. style & $24.6(5)$ & $27(5)$ & $25.5(4.9)$ & $24.1(6.1)$ & $23.9(5.6)$ & $24.1(5.6)$ & .803 \\
\hline \multicolumn{8}{|l|}{ Coping } \\
\hline Avoidant coping & $20.1(3.6)$ & $20.1(3)$ & $19.7(5.2)$ & $18.7(3.4)$ & $19.4(3.7)$ & $19.5(3.2)$ & .277 \\
\hline Passive coping & $14.1(3.1)$ & $14.2(2.8)$ & $17(2.6)$ & $14.9(3.2)$ & $14.5(2.9)$ & $15.6(2.7)$ & 1.606 \\
\hline Active coping & $20.9(3.2)$ & $19.3(2.9)$ & $17.7(2.9)$ & $18.6(2.9)$ & $18.9(3.4)$ & $18.2(3.1)$ & 2.142 \\
\hline \multicolumn{8}{|l|}{ Personality } \\
\hline Autonomy & $79.3(7.1)$ & $73.1(10.7)$ & $70(11.2)$ & $73.6(13)$ & $70(12)$ & $69.2(10)$ & 1.872 \\
\hline Conscientiousness & $69.7(10)$ & $61.9(12.3)$ & $61.7(10.9)$ & $65.6(13.3)$ & $68.2(11.4)$ & $69.4(11.3)$ & 1.226 \\
\hline Emotional stability & 77.0a (8.3) & 71.8ab (10.4) & $64.2 b(11.9)$ & 68.7ab (9.1) & $66.4 \mathrm{ab}(8.7)$ & 70.6ab (9.9) & $3.012 * *$ \\
\hline Agreeableness & $81.4(7.4)$ & $79.8(8.3)$ & $76.1(15.7)$ & $78.3(10.7)$ & $78.6(7.8)$ & $76.4(8.7)$ & .544 \\
\hline Ego development & $4.9(.58)$ & $4.8(.3)$ & $4.9(.41)$ & $4.7(.34)$ & $5.0(.39)$ & $5.2(.47)$ & 1.46 \\
\hline
\end{tabular}

Note: Means with different letters in the same row differ significantly at $p<.05$ using Bonferroni's multiple comparisons procedure $* * p<.01 ; * * * p<.001$

clusters. The A and F cluster show the highest levels of positive emotion and the lowest levels of negative emotion. The crisis cluster shows the least positive emotions and the most negative emotions. Passive coping is highest in the $\mathrm{M}$ cluster, and lowest in the $\mathrm{F}$ cluster (Table 11). 
Table 9 Friends: mean scores for well-being, identity styles, coping, personality, and maturity per cluster

\begin{tabular}{|c|c|c|c|c|c|c|}
\hline & $\begin{array}{l}\text { Cluster } 1 \\
\mathrm{DF}(n=24)\end{array}$ & $\begin{array}{l}\text { Cluster } 2 \\
\mathrm{~F}(n=26)\end{array}$ & $\begin{array}{l}\text { Cluster } 3 \\
\text { MA }(n=14)\end{array}$ & $\begin{array}{l}\text { Cluster } 4 \\
\text { A }(n=16)\end{array}$ & $\begin{array}{l}\text { Cluster } 5 \\
\mathrm{AM}(n=12)\end{array}$ & $F$ \\
\hline Perceived change & $0.9(1.06)$ & $0.7(.96)$ & $1.2(1.14)$ & $1(1.4)$ & $1.6(1.3)$ & 1.279 \\
\hline Positive emotions & $3.2(1.2)$ & $3.4(.99)$ & $3.1(.86)$ & $3.2(1.2)$ & $2.5(1.1)$ & 1.581 \\
\hline Negative emotions & $0.3(.61)$ & $0.2(, 51)$ & $0.7(1.03)$ & $0.9(1.1)$ & $0.9(1.04)$ & $2.888^{*}$ \\
\hline \multicolumn{7}{|l|}{ Identity style } \\
\hline Inform. style & $37.3 \mathrm{a}(5.3)$ & $38.3 \mathrm{a}(5.3)$ & 37.9ab (5.1) & $43.3 \mathrm{~b}(4.2)$ & 41.1ab (6) & $3.927 * *$ \\
\hline Norm. style & $25.6(4.3)$ & $27.3(5)$ & $27.1(4.7)$ & $27.5(4.9)$ & $24.6(5.5)$ & .974 \\
\hline Diff. style & $25.8(5.3)$ & 23.7 (4.9) & $26.8(5.9)$ & $24.3(5.6)$ & $25.2(4.8)$ & .948 \\
\hline \multicolumn{7}{|l|}{ Coping } \\
\hline Avoidant coping & $18.5(2.8)$ & $19.4(4.2)$ & $18.9(3.4)$ & $21.5(2.9)$ & $21.7(3)$ & $2.866^{*}$ \\
\hline Passive coping & 13.8a (3.2) & $13.9 \mathrm{a}(3)$ & $17 \mathrm{~b}(2.2)$ & $14.9 \mathrm{ab}(2.4)$ & $15.8 \mathrm{ab}(2.6)$ & $3.524^{*}$ \\
\hline Active coping & $19 \mathrm{ab}(3.2)$ & $20.4 b(3.3)$ & $17 \mathrm{a}(3.4)$ & $19.6 \mathrm{ab}(2.6)$ & 19.9ab (2.7) & $2.945^{*}$ \\
\hline \multicolumn{7}{|l|}{ Personality } \\
\hline Autonomy & $68.2(10.5)$ & $77.8(10.3)$ & $69.7(12.3)$ & $77.3(7.7)$ & $72.8(9.7)$ & $2.875^{*}$ \\
\hline Conscientiousness & $64.6(12.1)$ & $70.5(10.3)$ & $63.9(10.8)$ & $61(15.2)$ & $68.6(7.8)$ & 1.627 \\
\hline Emotional stability & $70(11.9)$ & $74.6(10.2)$ & $66(10.3)$ & $70.9(8.7)$ & $69.5(8)$ & 1.486 \\
\hline Agreeableness & $76.6(10)$ & $81(7)$ & $78.8(12.5)$ & $76.4(7.4)$ & $82.2(9.8)$ & 1.020 \\
\hline Ego development & $4.8(.48)$ & $4.8(.53)$ & $4.9(.21)$ & $5(.49)$ & $5.1(.36)$ & 1.030 \\
\hline
\end{tabular}

Note: Means with different letters in the same row differ significantly at $p<.05$ using Bonferroni's multiple comparisons procedure $* p<.05 ; * * p<.01$

Table 10 School, work, and leisure: mean scores for well-being, identity styles, coping, personality, and maturity per cluster

\begin{tabular}{|c|c|c|c|c|c|c|c|}
\hline & $\begin{array}{l}\text { Cluster } 1 \\
\text { A }(n=18)\end{array}$ & $\begin{array}{l}\text { Cluster } 2 \\
\mathrm{AM}(n=12)\end{array}$ & $\begin{array}{l}\text { Cluster } 3 \\
\mathrm{M}(n=17)\end{array}$ & $\begin{array}{l}\text { Cluster } 4 \\
\text { MA }(n=9)\end{array}$ & $\begin{array}{l}\text { Cluster } 5 \\
\mathrm{~F}(n=22)\end{array}$ & $\begin{array}{l}\text { Cluster } 6 \\
\text { FM }(n=14)\end{array}$ & $F$ \\
\hline Perceived change & $1.3 \mathrm{ab}(1.4)$ & $2.6 a(1.1)$ & $1.8 \mathrm{ab}(.88)$ & $2 \mathrm{ab}(1.3)$ & $0.9 \mathrm{~b}(1.3)$ & $2 \mathrm{ab}(1.3)$ & $2.977 * *$ \\
\hline Positive emotions & $3.3 \mathrm{a}(.65)$ & $1.8 \mathrm{~b}(1.1)$ & $2.8 \mathrm{ab}(1)$ & 2.9ab (1.2) & $3.6 a(.78)$ & $3 \mathrm{ab}(1.1)$ & $5.751 * * *$ \\
\hline Negative emotions & $0.2 \mathrm{a}(.55)$ & $2.3 b(.78)$ & $1.2 \mathrm{c}(1)$ & $0.3 \mathrm{ac}(.46)$ & $0.1 \mathrm{a}(.69)$ & $0.7 \mathrm{ac}(.93)$ & $13.791 * * *$ \\
\hline \multicolumn{8}{|l|}{ Identity style } \\
\hline Inform. style & $40.7(6.2)$ & $39.3(4.9)$ & $39.5(4.6)$ & $36.3(5.6)$ & $39(5.5)$ & $39.4(5.9)$ & 1.069 \\
\hline Norm. style & $27.6(4.6)$ & $26.3(4.6)$ & $25.5(5.6)$ & $26.8(3.4)$ & $27.6(5.4)$ & $24.5(4.3)$ & .664 \\
\hline Diff. style & $26.7(5.4)$ & $25.9(5.8)$ & $24.4(5.2)$ & $24.9(5.9)$ & $23.1(4.9)$ & $25.1(5.1)$ & .775 \\
\hline \multicolumn{8}{|l|}{ Coping } \\
\hline Avoidant coping & $20.3(3.5)$ & $19.9(2.7)$ & $20.3(4.1)$ & $17.6(2.4)$ & $19.1(3.9)$ & 20.7 (3.6) & .813 \\
\hline Passive coping & $15.4 \mathrm{ab}(2.1)$ & $15.8 \mathrm{a}(2.5)$ & $16.8 \mathrm{a}(2.9)$ & $14.3 \mathrm{ab}(2.4)$ & $12.6 \mathrm{~b}(2.8)$ & 14.9ab (5.6) & $4.340 * *$ \\
\hline Active coping & $19.5(3.9)$ & $18.3(3.1)$ & $18.3(3.2)$ & $19.2(3.6)$ & $20.5(2.6)$ & $19.2(2.5)$ & 1.194 \\
\hline \multicolumn{8}{|l|}{ Personality } \\
\hline Autonomy & $72.5(9.9)$ & $70.2(12)$ & $69.8(11.3)$ & $77.4(14.7)$ & $76.5(8.7)$ & $74.6(9.6)$ & .982 \\
\hline Conscientiousness & $65.7(11.2)$ & $62.9(13.6)$ & $60.4(14.4)$ & $64.9(11.1)$ & $71.8(8)$ & $67.4(12.7)$ & 1.330 \\
\hline Emotional stability & $71.4(9.6)$ & $66.3(8.2)$ & $67.3(12.3)$ & $74(8.7)$ & $74.9(11.2)$ & $69.1(9.6)$ & 1.104 \\
\hline Agreeableness & $78.3(12.4)$ & $80(8.1)$ & $80.4(12)$ & $78(8.1)$ & $78.4(7)$ & $79.5(6.8)$ & .169 \\
\hline Ego development & $4.8(.55)$ & $5(.41)$ & $4.7(.36)$ & $4.8(.36)$ & $4.8(.46)$ & $5.1(.46)$ & 1.458 \\
\hline
\end{tabular}

Note: Means with different letters in the same row differ significantly at $p<.05$ using Bonferroni's multiple comparisons procedure $* * p<.01 ; * * * \quad p<.001$

In the domain of personal characteristics, most variables differ significantly between the clusters. Again, the moratorium- and change-clusters score highest on perceived change. Well-being (highly positive emotions and few negative ones) is highest in the foreclosed cluster and low in the moratorium-cluster, but the high score in the AM 
Table 11 Personal characteristics: mean scores for well-being, identity styles, coping, personality, and maturity per cluster

\begin{tabular}{|c|c|c|c|c|c|c|}
\hline & $\begin{array}{l}\text { Cluster } 1 \\
\mathrm{~F}(n=36)\end{array}$ & $\begin{array}{l}\text { Cluster } 2 \\
\text { MF }(n=9)\end{array}$ & $\begin{array}{l}\text { Cluster } 3 \\
\mathrm{M}(n=12)\end{array}$ & $\begin{array}{l}\text { Cluster } 4 \\
\mathrm{AM}(n=16)\end{array}$ & $\begin{array}{l}\text { Cluster } 5 \\
\text { MA }(n=19)\end{array}$ & $F$ \\
\hline Perceived change & $0.7 \mathrm{a}(1.1)$ & $1.7(1.0)$ & $1.5(1.1)$ & $2.1 \mathrm{ab}(1.3)$ & $0.7 \mathrm{~b}(0.7)$ & $6.369 * * *$ \\
\hline Positive emotions & $3.5 \mathrm{ab}(0.9)$ & $2.1 \mathrm{ac}(0.8)$ & $2.5 \mathrm{~b}(1.1)$ & $3.4 \mathrm{c}(0.9)$ & $3(0.9)$ & $5.859 * * *$ \\
\hline Negative emotions & $0.3 \mathrm{ab}(0.5)$ & $1.2 \mathrm{a}(1.2)$ & $1.6 \mathrm{~b}(1.1)$ & $0.8(1.2)$ & $0.7(0.8)$ & $6.268 * * *$ \\
\hline \multicolumn{7}{|l|}{ Identity style } \\
\hline Inform. style & $39.3(5.7)$ & $37.8(5.1)$ & $39.1(4.9)$ & $40.1(6.4)$ & $39.3(5.6)$ & 0.244 \\
\hline Norm. style & 6.9a (.4.9) & 21.1abcd (2.8) & $27.9 \mathrm{~b}(2.5)$ & $26.8 \mathrm{c}(4.6)$ & $27.4 \mathrm{~d}(4.6)$ & $3.672 * *$ \\
\hline Diff. style & $23.3(4.7)$ & $25.9(5.5)$ & $28(5.6)$ & $24.4(5.7)$ & $26.3(5.1)$ & 2.357 \\
\hline \multicolumn{7}{|l|}{ Coping } \\
\hline Avoidant coping & $14.7 \mathrm{a}(2.8)$ & $15.7 b(4.1)$ & 19.6abc (3.4) & $17.3(3.2)$ & $15.9 \mathrm{c}(2)$ & $6.193 * * *$ \\
\hline Passive coping & $13.2 \mathrm{a}(2.7)$ & $16.2 \mathrm{a}(3.4)$ & $17.8 \mathrm{ab}(2.2)$ & $15.4(2.3)$ & $14.4 \mathrm{~b}(2.4)$ & $7.963 * * *$ \\
\hline Active coping & $20.5 \mathrm{a}(2.8)$ & $20.1(3.2)$ & $16.9 \mathrm{a}(3.4)$ & $17.9(2.4)$ & $19.5(3.5)$ & $4.314 * *$ \\
\hline \multicolumn{7}{|l|}{ Personality } \\
\hline Autonomy & 77.5a (10.9) & $74(11.5)$ & 63.6a (8.5) & $70(10.4)$ & $75.1(7.6)$ & $3.973 * *$ \\
\hline Conscientiousness & 71.7a (9.6) & $63.3(15.6)$ & $64.6(8.6)$ & $60.2 \mathrm{a}(12.3)$ & $62.6(11.4)$ & $3.209 * *$ \\
\hline Emotional stability & $74.5(10.1)$ & $71(8.8)$ & $62.2(12.2)$ & $66.1(8.6)$ & $71.9(9.1)$ & $2.831 *$ \\
\hline Agreeableness & 79 (7.9) & $84.3(6.2)$ & $75.8(11.7)$ & 76.4 (7.6) & $79.1(12.2)$ & 1.880 \\
\hline Ego development & $5(0.4)$ & $4.6 \mathrm{a}(0.4)$ & $4.9(0.5)$ & $5.2 \mathrm{a}(0.5)$ & $5(0.4)$ & 2.149 \\
\hline
\end{tabular}

Note: Means with different letters in the same row differ significantly at $p<.05$ using Bonferroni's multiple comparisons procedure $* p<.05 ; * * p<.01 ; * * * p<.001$

cluster and the low score in the MA cluster (2), are contrary to our expectation. Surprisingly, normative identity style is highest in one of the MA clusters (5) and lowest in the other one (2). Autonomy is highest in the foreclosed cluster, and lowest in the moratorium-cluster. Active coping is higher in clusters with stable and emerging high commitments and avoidant and passive coping is highest in the moratorium-cluster. Conscientiousness and emotional stability are highest in the foreclosed cluster. Conscientiousness is lowest in the AM cluster and emotional stability is lowest in the moratorium-cluster. Well-being is highest in the F cluster and the gradual MA cluster and lowest in the moratorium- and diffused clusters, i.e., those without commitments. Ego development is lowest in the diffuse cluster and highest in the $\mathrm{M}$ and MA clusters. Active coping is lowest in the $\mathrm{M}$ cluster and highest in the F cluster (Table 12).

In the domain of intimate relationships we found least significant differences between the clusters. The F and MA cluster have-as expected-highest positive emotion scores. The high active coping scores in the AM and F clusters are contrary our expectations.

Because we are interested in the general tendencies of differences between clusters we present an overview per domain of the cluster with the highest (Table 13) and the lowest (Table 14) scores for each variable. In these tables we include only the variables that differ significantly between the clusters.

\section{Discussion II}

First, we will focus on the general tendencies of the relations between the clusters and the variables over all domains. Next, we will discuss the difference between domains.

Subjects in persistent moratorium- and change-trajectories perceived most change in their commitments, and subjects in stable foreclosed and achieved trajectories perceived least change. This indicates that change in commitment is something that is experienced consciously by the subjects at the moment the change takes places. In line with our hypotheses, well-being is lowest in the AM and $\mathrm{M}$ trajectories, and highest in the $\mathrm{F}$ and $\mathrm{A}$ trajectories. In all domains, trajectories with stable strong commitments have the highest positive and the lowest negative emotion scores. Lowest well-being scores are found in moratorium and change trajectories. Only the low well-being scores in the achieved cluster in domain friends run counter our expectations.

Identity style is not strongly related to the different trajectories. Only 3 out of 18 possible relations are significant. As expected, the highest scores for an information-oriented processing style are found in stable achieved trajectories. The lowest scores are found in the diffuse-foreclosed trajectories. The absence of any relations of the normative style may have to do with the low reliability of this scale (Bosma et al. 2002; Kunnen 2004). 
Table 12 Intimate relations: mean scores for well-being, identity styles, coping, personality, and maturity per cluster

\begin{tabular}{|c|c|c|c|c|c|c|}
\hline & $\begin{array}{l}\text { Cluster } 1 \\
\text { MA }(n=11)\end{array}$ & $\begin{array}{l}\text { Cluster } 2 \\
\mathrm{AM}(n=11)\end{array}$ & $\begin{array}{l}\text { Cluster } 3 \\
\mathrm{M}(n=17)\end{array}$ & $\begin{array}{l}\text { Cluster } 4 \\
\mathrm{~F}(n=33)\end{array}$ & $\begin{array}{l}\text { Cluster } 5 \\
\text { MA }(n=20)\end{array}$ & $F$ \\
\hline Perceived change & $1.9(0.3)$ & $1.3(0.4)$ & $1.1(0.3)$ & $0.8(0.2)$ & $0.7(2)$ & 2.268 \\
\hline Positive emotions & $2.7(0.7)$ & $3.1(0.9)$ & 1.8abc (1.4) & $3.5 b(0.9)$ & $3.7 \mathrm{c}(0.8)$ & $10.690 * * *$ \\
\hline Negative emotions & $0.5(0.9)$ & $0.4(0.7)$ & $0.9(1.1)$ & $0.5(0.7)$ & $0.2(0.4)$ & 2.391 \\
\hline \multicolumn{7}{|l|}{ Identity style } \\
\hline Inform. style & $39.6(6.2)$ & $39.6(6.0)$ & $36.9(4.5)$ & $39.2(5.0)$ & $41.1(6.5)$ & 1.226 \\
\hline Norm. style & $27.4(5.3)$ & $24.0(5.1)$ & $26.7(4.0)$ & $26.8(5.1)$ & $26.8(4.7)$ & 0.802 \\
\hline Diff. style & $25.6(4.5)$ & $24.3(3.7)$ & $26.9(6.6)$ & $23.6(5.3)$ & $25.9(5.1)$ & 1.343 \\
\hline \multicolumn{7}{|l|}{ Coping } \\
\hline Avoidant coping & $17.3(5.2)$ & $14.9(3.3)$ & $17.6(3.8)$ & $15.5(2.5)$ & $16.2(3.0)$ & 1.693 \\
\hline Passive coping & $15.7(2.3)$ & $15.2(3.0)$ & $15.4(3.5)$ & $14.3(3.1)$ & $14.3(2.7)$ & 0.780 \\
\hline Active coping & $17.8(2.6)$ & $20.3 \mathrm{a}(2.7)$ & 16.9ab (3.6) & $20.7 \mathrm{~b}(2.8)$ & $19.6(2.9)$ & $5.612 * * *$ \\
\hline \multicolumn{7}{|l|}{ Personality } \\
\hline Autonomy & $69.5(13.5)$ & $75.6(8.9)$ & 67.7 (11.9) & $76.5(10.2)$ & $75.5(8.6)$ & 2.132 \\
\hline Conscientiousness & $62.1(14.0)$ & $63.1(14.2)$ & $61.7(12.4)$ & $71.3(8.6)$ & $66.9(10.7)$ & 2.134 \\
\hline Emotional stability & $71.0(11.5)$ & $72.1(4.6)$ & $66.1(11.0)$ & $71.7(10.6)$ & $72.9(10.9)$ & 1.039 \\
\hline Agreeableness & $77.5(10.0)$ & $82.8(8.1)$ & $77.5(10.2)$ & $79.0(11.5)$ & $79.1(6.0)$ & 0.534 \\
\hline Ego development & $4.9(0.3)$ & $4.8(0.3)$ & $4.8(0.4)$ & $4.9(0.4)$ & $5.1(0.6)$ & 1.678 \\
\hline
\end{tabular}

Note: Means with different letters in the same row differ significantly at $p<.05$ using Bonferroni's multiple comparisons procedure $* * * p<.001$

Table 13 The cluster with the highest scores for each domain

\begin{tabular}{lllllll}
\hline Variable/domain & 1 & 2 & 3 & 4 & 5 & 6 \\
\hline Perceived change & AM+M & MA & & AM & AM & \\
Positive emotions & A & F & & F+A & F & MA \\
Negative emotions & & M & A+AM & AM & MA & \\
Inform. style & A & & A & & & \\
Norm. style & & & & & M & \\
Diff. style & & & & & & \\
Avoidant coping & & & AM & & M & \\
Passive coping & & & MA & M & M & \\
Active coping & A+AM & & F & & F & F \\
Autonomy & & & F+A & & F & \\
Conscientiousness & & & & & F & \\
Emotional stability & & F & & & F & \\
Agreeableness & & & & & & \\
Ego-development & A & & & & & \\
\hline
\end{tabular}

Most probably, this low reliability is caused by the diversity in content and formulation of the items (Smits et al. in preparation).

Coping shows more significant differences, especially in the domains of friendship and personal characteristics. In the domain of friendship, the clusters with low exploration scores (DF and F) show most active and least passive and avoidant coping, while the change-clusters MA and AM show the opposite pattern. It might be that having stable
Table 14 The cluster with the lowest scores for each domain

\begin{tabular}{lllllll}
\hline Variable/domain & 1 & 2 & 3 & 4 & 5 & 6 \\
\hline Perceived change & D & F & & F & F+MA & \\
Positive emotions & AM & M+AM1 & & AM1 & MA & M \\
Negative emotions & D & F & DF+F & F & F & \\
Inform. style & & & DF & & & \\
Norm. style & & & & & MA & \\
Diff. style & & & & & & \\
Avoidant coping & & & DF & & F & \\
Passive coping & & & DF+F & F & F & \\
Active coping & M & & MA & & M & M \\
Autonomy & & & DF & & M & \\
Conscientiousness & & & & & AM & \\
Emotional stability & & M & & & M & \\
Agreeableness & & & & & & \\
Ego-development & D+MA & & & & & \\
\hline
\end{tabular}

and unquestioned friendship relations may help one in active coping with problems. Or, active coping may help to keep friendships stable and unquestioned. In the domain of personal characteristics, the clusters with strong commitments and low exploration levels show most active coping, while the $\mathrm{M}$ cluster shows most passive and avoidant, and least active coping.

These findings suggest that active coping is higher in subjects who do have strong commitments, regardless of 
whether these commitments are self-chosen. This is against our expectations. An explanation can be found in theories that focus on situation-related determinants of coping. Active coping is especially effective in situations with low ambiguity, high controllability and high valence (Boekaerts 1996). We may expect that having strong commitmentsknowing who one is, what one wants and where one is going-increases the perception of controllability, decreases the perception of ambiguity, and in this way increases the preference for active coping. In a moratorium-status, difficult events are probably perceived as much more ambiguous and uncontrollable. Such situations trigger avoidant coping.

As regards personality characteristics, there are only few significant differences (5 out of 24). Most significant differences in personality characteristics are found in the domain of personal characteristics and in all cases, the stable foreclosed trajectories have the highest scores, while $\mathrm{M}$ and change-trajectories have the lowest scores. We think this is an interesting finding, because the domain of personal characteristics is the domain that is probably least directly influenced by contextual changes. If contextual demands (such as the necessity to choose a major or to leave home) stimulate commitment development, the way people cope with those demands will affect commitment development. In the relative absence of such external pressure, underlying personality characteristics may play a more important role in commitment formation. Another explanation stems from the fact that almost all our instruments are based on self report. There may be a general way of presenting oneself: subjects who present themselves in terms of strong commitments, also present themselves in terms of clear and salient personalities. These are subjects who present themselves as people who know who they are and who have few doubts.

Trajectories characterized by change (M and AM and DF) have lowest scores on autonomy, conscientiousness, and emotional stability. It may be that subjects who do not know what they want, and do not feel good about their commitments, perceive themselves as less agreeable, conscientious and emotionally stable than when they do have commitments that help them to know who they are and where they want to go.

Differences in ego development are significant in the domain of philosophy of life only. As expected, moratorium and MA have the highest scores and crisis and diffuse trajectories the lowest.

In our discussion concerning the cluster characteristics, we suggested that the diffuse-foreclosed (DF) cluster in the domain of friends might represent the development of achieved commitments, comparable to a moratoriumachieved (MA) trajectory, because exploration might be less important in this domain. The low scores on passive and avoidant coping can be expected in an MA trajectory, but we would not expect low scores on informationoriented identity style and autonomy. However, these scores are in line with our third explanation which was based on Blustein and Phillips' (1990) notion of an intuitive and dependent decision making style. If people seek out rapid and other-dependent solutions to decisional tasks they probably show little information orientation and autonomy. A more thorough analysis of the contents of the commitments is needed to understand this cluster. Such an analysis however, is beyond the scope of this paper.

In the domain of parents, we found two Foreclosed clusters. In the cluster analysis they have been separated because of differences that have little theoretical meaning (the commitment strength is high in both, but in cluster 1 still higher than in cluster 2), and the change in commitments is very small but positive in the one, and negative in the other cluster. Also with regard to the relation with other variables, the clusters show a comparable pattern, except with regard to the emotional stability, which is highest in the cluster with the highest commitment scores.

\section{General Conclusion}

In this paper, we present evidence for our theoretical expectations concerning the shape of individual trajectories in commitment development. Almost all clusters can be classified either somewhere on the MAMA trajectory, or as a stable trajectory in one of the four identity statuses. Our expectations concerning the differences between clusters are generally confirmed for the variables perceived change, well-being and ego-development. The results with regard to coping and personality are less consistent with our expectations. In general, the condition "having no commitments for a prolonged period" seemed to be more strongly related to non-optimal outcomes than "no exploration." This is surprising, given the important role of exploration in identity development. The findings can be explained by the influence of the actual condition (having no commitments and not knowing where to go) on coping and on self-reported personality traits. This suggests that in understanding differences in identity development, we should focus on the effects of functioning and characteristics on identity development, as well as on effects of the identity status on the subject's functioning and characteristics. Having strong commitments may make one happy and well-functioning, while having high exploration levels may be not so positive in the short term. This is not so surprising. Exploration as assessed by the GIDS includes both exploration in depth and exploration in breadth (Luyckx 2006), and is related to the emergence of conflicts (Kunnen 2006). The differences that are found between M, MA, AM, and A clusters suggest that, although in identity theory people in an $\mathrm{M}$ and an A status are 
often seen as comparable in many respects, the actual situation of having (A), developing (MA), loosing (AM) not having $(\mathrm{M})$ may affect coping, well-being, and even the perception of one's own traits.

We studied identity development in different domains. Although our focus was not primarily on domain characteristics, our results show some interesting differences that could be interpreted in terms of developmental mechanisms relevant in identity development, and shed some light on the role of contextual factors in this development. The low levels of change and exploration in the domain "parents" is consistent with developmental task literature. Havighurst $(1948,1972)$ states that to acquire "an independence from parents" belongs to the challenges of adolescence, while making choices in the professional domain, in the domains of intimate relationship and social groups are more typical of emerging adulthood. In addition, the transition to university is a change in context that may demand identity change in many domains. Especially for students who stay to live with their parents (about $50 \%$ in the Netherlands), the relation with the parents may be one of the stable factors during this period. Also the high number of diffused trajectories in the philosophy of life domain suggests that contextual demands play a role. Religion and politics do not play an important role in the dominant student culture at Dutch universities and the context does not pose strong demands to develop commitments in this domain. Finally, the findings suggest that the role of exploration in identity development is not the same in every domain.

The study has its limitations. First, the subjects were all students in psychology of a traditional university in the north of the Netherlands, thus highly educated, and predominantly female. This may have affected the scores on all instruments, and it reduced the contextual variation. Especially the differences between domains may have been caused by contextual factors and demands that are specific for this sample. However, the homogeneity of the sample also has major advantages, because the differences that were found cannot be explained by differences between the subjects in terms of gender and educational level. Moreover, we expect that our conclusions concerning the shape of the development may be less dependent on specificities of the sample. There is no evidence that underlying mechanisms differ in different subgroups. Of course, more research into other groups is needed to confirm this assumption. Another limitation of the study is that all measurements in this study are based on self-report. Although this is a common approach in identity research, in future research it is recommended to add more behavior-based measures, for example observations of the way subjects cope with real problems. Another approach of this limitation may be to include the natural fluctuations in self-report as part of the dynamics of the concept under study (see for example Schwarz and Oyserman 2001). Finally, studying development on the basis of two data points is limited. The clusters show only a small part of the assumed trajectory that is assumed, and additional research, based on more data points and a longer time period will be needed. However, most research in identity development is based on single assessments only. Moreover, the fact that our research shows different types of change patterns suggests that the careful selection of a transitional period-such as entering university - as the focus of study, might be very important in the study of change. This study can be seen as a first step in the study and validation of a really developmental model of identity development.

\section{Appendix}

\begin{tabular}{|c|c|c|c|c|c|c|}
\hline \multirow[t]{2}{*}{ Cluster solution } & \multicolumn{6}{|c|}{ Fusion coefficients } \\
\hline & Domain 1 & Domain 2 & Domain 3 & Domain 4 & Domain 5 & Domain 6 \\
\hline 9 clusters & 2866.06 & 2809.13 & 2776.35 & 2893.74 & 3044.68 & 2914.64 \\
\hline 8 clusters & 3096.02 & 3091.66 & 3086.94 & 3208.04 & 3271.60 & 3209.22 \\
\hline 7 clusters & 3486.94 & 3376.89 & 3439.43 & 3533.41 & 3530.13 & 3541.98 \\
\hline 6 clusters & 3901.03 & 3688.86 & 3899.7 & 3881.4 & 3990.83 & 3923.80 \\
\hline 5 clusters & 4355.15 & 4069.98 & 4429.98 & 4449.76 & 4532.91 & 4391.40 \\
\hline 4 clusters & 5047.2 & 4704.23 & 5093.48 & 5077.44 & 5231.41 & 5162.49 \\
\hline 3 clusters & 5858.84 & 5782.96 & 5875.52 & 5964.88 & 6306.72 & 6272.29 \\
\hline 2 clusters & 8073.29 & 7160.81 & 7133.21 & 8229.99 & 8591.00 & 8573.45 \\
\hline 1 cluster & 10910.16 & 10351.9 & 9667.99 & 12203.65 & 11913.77 & 11554.94 \\
\hline
\end{tabular}

Note: Agglomeration schedule hierarchical analysis cluster solutions: Ward's linkage method, Square Euclidean distance 
Open Access This article is distributed under the terms of the Creative Commons Attribution Noncommercial License which permits any noncommercial use, distribution, and reproduction in any medium, provided the original author(s) and source are credited.

\section{References}

Berzonsky, M. D. (1990). Self-construction over the life span: A process perspective on identity formation. In G. J. Neimeyer \& R. A. Neimeyer (Eds.), Advances in personal construct psychology (Vol. 1, pp. 155-186). Greenwich, CT: JAI Press.

Berzonsky, M. D. (1992). Identity style and coping strategies. Journal of Personality, 60, 771-778.

Berzonsky, M. D., \& Sullivan, C. (1992). Social-cognitive aspects of identity style: need for cognition, experiential openness, and introspection. Journal of Adolescent Research, 7, 140-155.

Bijstra, J., Jackson, S., \& Bosma, H. A. (1994). De Utrechtse coping lijst voor adolescenten (UCL-A). Kind \& Adolescent, 1994(15), 98-109.

Blustein, D. L., \& Phillips, S. D. (1990). Relation between ego identity statuses and decision making styles. Journal of Counselling Psychology, 37, 160-168.

Boekaerts, M. (1996). Coping with stress in childhood and adolescence. In M. Zeidner \& N. S. Endler (Eds.), Handbook of coping (pp. 452-484). New York: Wiley and Sons.

Bonica, L., \& Sappa, V. (2006). The need for "shared challenges": successful training experiences among former school dropouts. In A. Delle Fave (Ed.), Dimensions of well being. Research and intervention (pp. 328-348). Milan: Franco Angeli.

Borgen, F. H., \& Barnett, D. C. (1987). Applying cluster analysis in counseling psychology research. Journal of Counseling Psychology, 34, 456-468.

Bosma, H. A. (1985). Identity development in adolescence. Coping with commitments. Unpublished doctoral dissertation, Groningen.

Bosma, H. A., \& Gerlsma, C. (2003). From early attachment relations to the adolescent and adult organisation of self. In J. Valsiner \& K. J. Connolly (Eds.), Handbook of developmental psychology (pp. 450-488). London: Sage.

Bosma, H. A., \& Kunnen, E. S. (2001). Determinants and mechanisms in identity development: a review and synthesis. Developmental Review, 21, 39-66.

Bosma, H. A., Schrooten, I., \& Zijsling, D. (2002). The adaptation to change in young adulthood: Differences between groups. Presentation at the EARA, September 2002, Oxford.

Clancy, S. M., \& Dollinger, S. J. (1993). Identity, self, and personality: Identity status and the five-factor model of personality. Journal of Research on Adolescence, 3, 227-245.

Côté, J. E., \& Levine, C. (1987). A formulation of Erikson's theory of ego identity formation. Developmental Review, 7, 273-325.

Everitt, B. S., Landau, S., \& Leese, M. (2001). Cluster analysis. London: Arnold.

Fadjukoff, P., Pulkkinen, L., \& Kokko, K. (2005). Identity processes in adulthood: diverging domains. Identity, 5, 1-20.

Hendriks, A. A. J., Hofstee, W. K. M., \& De Raad, B. (1999). The five factor Personality Inventory (FFPI). Personality and Individual Differences, 51, 79-88.
Havighurst, R. J. (1972). Developmental tasks and education. New York: David McKay (Original work published 1948).

Kroger, J. (1995). The differentiation of "firm" and "developmental" foreclosure identity statuses: A longitudinal study. Journal of Adolescent Research, 10, 317-337.

Kunnen, E. S. (2004). Analysis of an instrument for assessment of identity styles: the ISI. Internal report. Groningen: Deparment of Clinical and Developmental Psychology, University of Groningen.

Kunnen, E. S. (2005, February). Developmental trajectories in identity. Presentation at SRIF conference, Miami.

Kunnen, E. S. (2006). Are conflicts the motor in identity change? Identity. International Journal of Theory and Research, 6, 169-186.

Kunnen, E. S. (2008). Characteristics and prediction of identity conflicts in 1st year students. Manuscript submitted for publication.

Kunnen, E. S., Bosma, H. A., \& van Geert, P. L. C. (2001). A dynamic systems approach to identity formation: Theoretical background and methodological possibilities. In J.-E. Nurmi (Ed.), Navigating through adolescence: European perspectives (pp. 247-274). Michigan State University Series on Children, Youth and families. New York: Garland Publishing.

Luyckx, K. (2006). Identity Formation in Emerging Adulthood. Developmental trajectories, antecedents, and consequences. Dissertation at the Catholic University of Leuven.

Marcia, J. E. (1966). Development and validation of ego identity status. Journal of Personality and Social Psychology, 3, 551-558.

Marcia, J. E. (1989). Identity diffusion differentiated. In M. A. Luszcz \& T. Nettelbeck (Eds.), Psychological development: Perspectives across the life span (pp. 289-318). North Holland: Elsevier Science Publishers.

Marcia, J. E. (1993). The status of the statuses: Research review. In J. E. Marcia, A. S. Waterman, D. R. Matteson, S. L. Archer, \& J. L. Orlofsky (Eds.), Ego identity. A handbook for psychosocial research (pp. 22-41). New York: Springer Verlag.

Schwarz, N., \& Oyserman, D. (2001). Asking questions about behavior: Cognition, communication, and questionnaire construction. American Journal of Evaluation, 22, 127-160.

Smits, I., Soenens, B., Berzonsky, M. D., Luyckx, K., Goossens, L., Kunnen, E. S., \& Bosma, H. A. (in preparation). The identity style inventory-version 4: A Cross-National Study in Scale Development and Validation.

Stephen, J., Fraser, E., \& Marcia, J. E. (1992). Moratoriumachievement (Mama) cycles in lifespan identity development: value orientations and reasoning system correlates. Journal of Adolescence, 15, 283-300.

Vleioras, G. (2005). Identity and emotion. An overlooked link. Dissertation. Groningen, stichting Kinderstudies.

Ward, J. H. (1963). Hierarchical grouping to optimize an objective function. Journal of the American Statistical Association, 58, 236-244.

Westenberg, P. M., Drewes, M. J., Siebelink, B. M., Treffers, Ph. D. A., Jonckheer, J., \& Goedhart, A. J. (2000). Verantwoording en toepassing van een instrument voor Ego Ontwikkeling. Zinnenaanvullijst Curium (deel 1 en 2). Lisse, Swets Test Publishers. 